University of Massachusetts Amherst

ScholarWorks@UMass Amherst

Environmental \& Water Resources Engineering

Masters Projects

2020

\title{
Optimizing Household Water Decisions for Managing Intermittent Water Supply in Mexico City
}

Savannah Wunderlich

University of Massachusetts Amherst

Follow this and additional works at: https://scholarworks.umass.edu/cee_ewre

Part of the Environmental Engineering Commons

Wunderlich, Savannah, "Optimizing Household Water Decisions for Managing Intermittent Water Supply in Mexico City" (2020). Environmental \& Water Resources Engineering Masters Projects. 102.

Retrieved from https://scholarworks.umass.edu/cee_ewre/102

This Article is brought to you for free and open access by the Civil and Environmental Engineering at ScholarWorks@UMass Amherst. It has been accepted for inclusion in Environmental \& Water Resources Engineering Masters Projects by an authorized administrator of ScholarWorks@UMass Amherst. For more information, please contact scholarworks@library.umass.edu. 


\section{Optimizing Household Water Decisions for Managing Intermittent Water Supply in Mexico City}

A Masters Project Presented

by

\section{Savannah Wunderlich}

Approved as to style and content by:

$$
\text { Emily kumpel }
$$

Dr. Emily Kumpel, Chairperson

$$
\text { Casey Brown }
$$

Dr. Casey Brown, Member

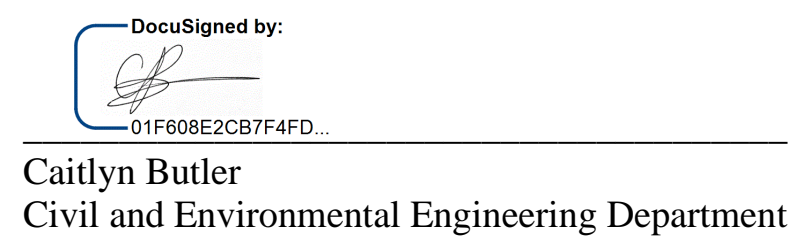




\section{Acknowledgements}

This work would not have been possible without the help and support of many different people and institutions. Funding was provided by the University of Massachusetts Amherst College of Engineering. I would like to thank our partners at the World Bank and the Sistema de Aguas de la Ciudad de México (SACMEX). I am grateful to Sarah St. George Freeman for helping to develop this project and for always being available to help when I ran into issues, and to Luisa Galindo who conducted the household interviews and helped to compile the results. I would like to thank my advisors, Dr. Emily Kumpel and Dr. Casey Brown who provided valuable feedback and support throughout this project. Finally, I am grateful to my family for their constant support. 


\section{Abstract}

Nearly 1 billion people around the world experience intermittent water supply (IWS), including about $70 \%$ of residents in the Mexico City area. Households with IWS often rely on multiple sources of water to meet their needs, including municipal piped water, trucked water, and rainwater. When calculating water costs and reliability of supply, models of these systems must account for household decision-making regarding the volume of water to use from each different source each day. Modeling these household decisions (or "control policies") is challenging, especially when households use rainwater as a water source, due to the complexity of the input variables involved (e.g. intermittent water schedule, season, day of week), but is critical to understanding the role that household-level interventions, such as household storage and rainwater harvesting, may play in water access. Universal approximators provide a solution to this challenge by allowing for flexible shaping of these control polices. This study uses Radial Basis Function Networks to determine optimal household water management decisions, maximizing reliability of water supply while minimizing costs for an arbitrary household in Mexico City. The model design is informed using data collected during interviews with households in the city. The model produces Paretooptimal solution sets that demonstrate which household-level investments are most effective for improving the reliability of water access. Results show that household storage tanks are a critical component of water access, especially in households with very low access to the municipal piped water supply. A tank volume of around 1500-2500 liters can provide most of the savings, depending on the availability of municipal water, although a larger tank is better able to collect rainwater. IWS households with sufficient storage are able to meet their water needs with piped water nearly as reliably as those with continuous water supply, as long as a minimal threshold of water is delivered. When household storage is limited, households are more vulnerable to disruptions in the piped network, and costs increase if supply is not delivered consistently. Rainwater harvesting systems are shown to be economically viable at the 
household level regardless of the frequency of municipal piped water service. The techniques presented in this study are a crucial step in modeling water resources in cities with IWS. 


\section{Table of Contents}

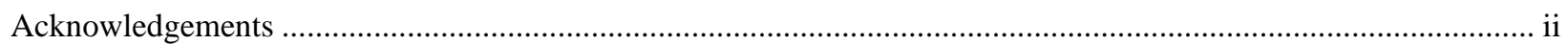

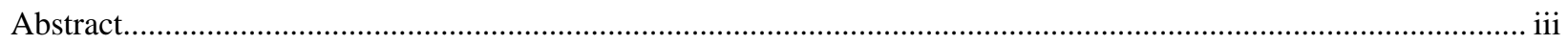

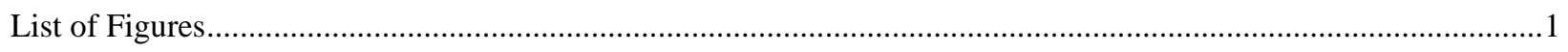

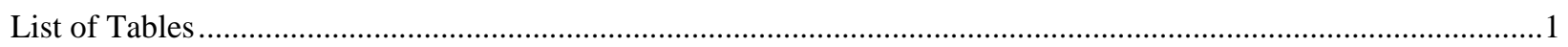

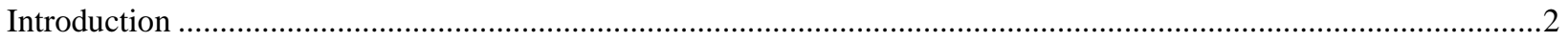

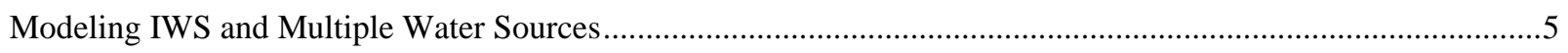

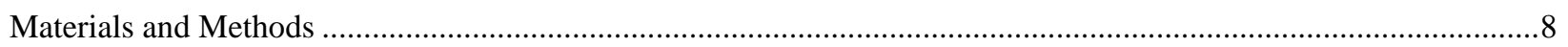

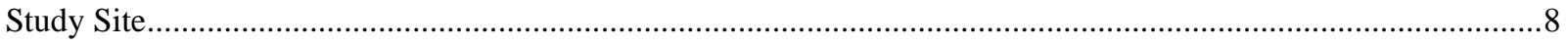

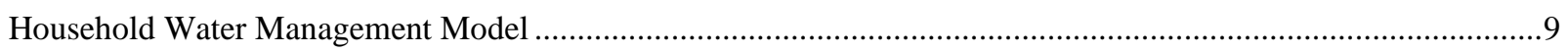

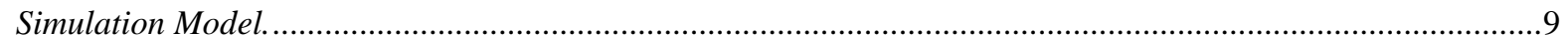

Optimization Model: Management Objectives. ………….......................................................................10

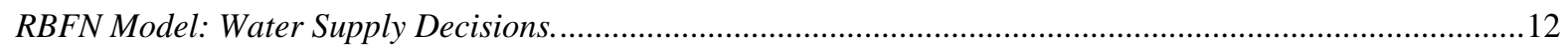

Model Construction through Household interviews .....................................................................................13

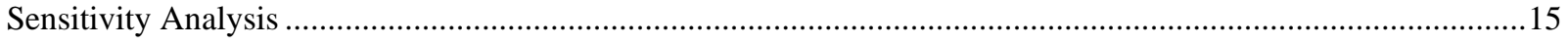

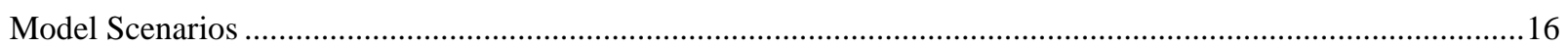

Varying IWS Schedules and Household Water Infrastructure Investments ...................................................16

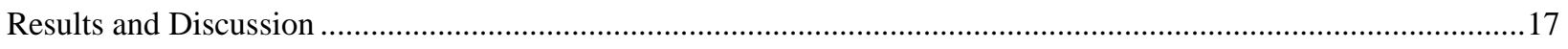

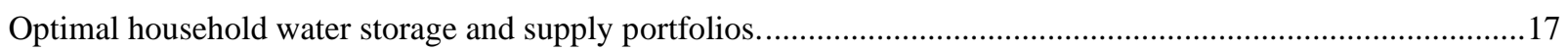

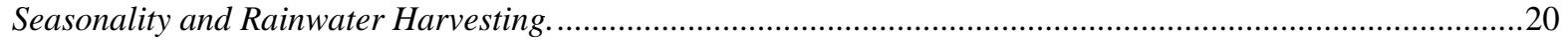

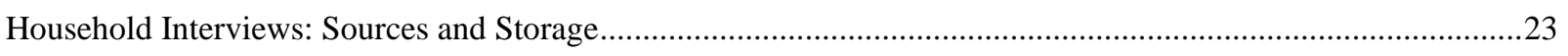

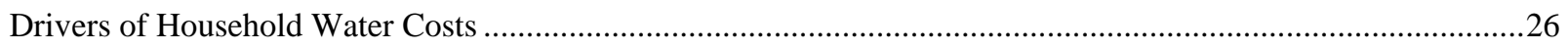

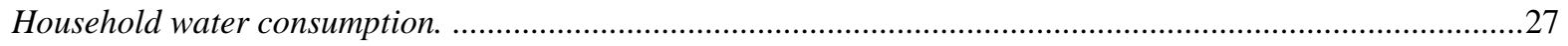

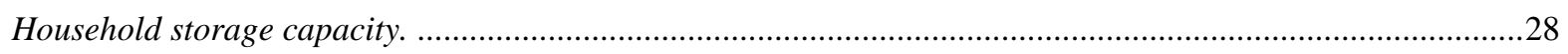

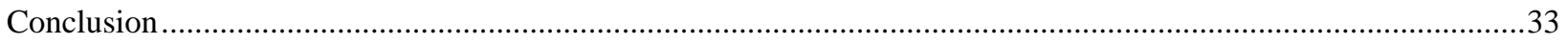

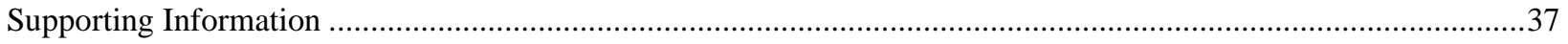

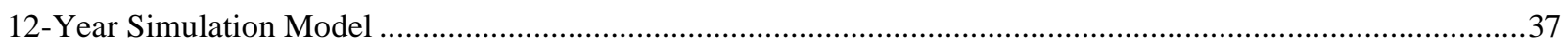

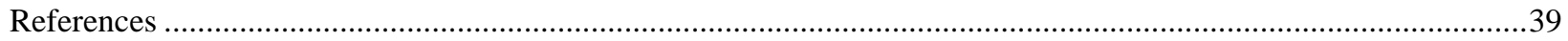




\section{List of Figures}

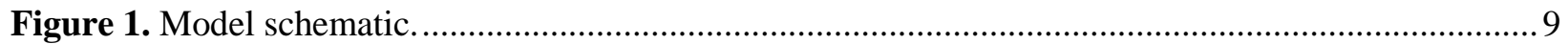

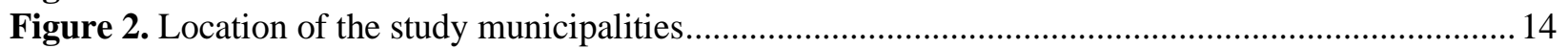

Figure 3. Household cost and reliability trade-off and optimal tank size for various scenarios ................ 19

Figure 4. Annual cost of water supply for reliability of $95 \%$ at varying hours of municipal piped water

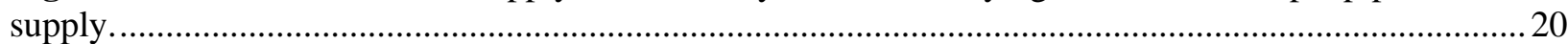

Figure 5. Fraction of water provided by each source ............................................................. 21

Figure 6. One-at-a-time (local) sensitivity analysis results..............................................................26

Figure 7. Coping costs at $95 \%$ reliability for varying household characteristics..................................29

Figure 8. Household cost and reliability trade-off under a set, limited storage volume of 500 liters........ 31

Figure 9. Fraction of water provided by each water source seasonally when storage was limited to $500 \mathrm{~L}$

\section{List of Tables}

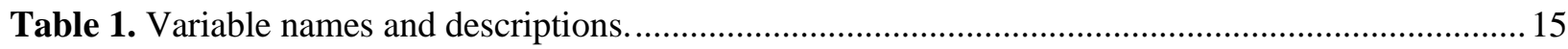

Table 2. Municipal Piped Water Supply Scenarios ..................................................................... 17

Table 3. Average annual water costs for households with and without rainwater harvesting for three piped

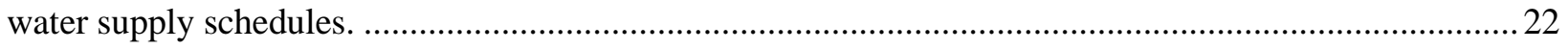

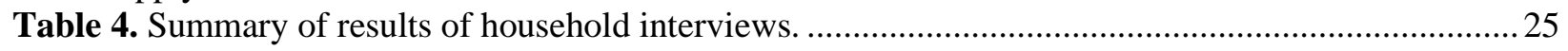




\section{Introduction}

Nearly 1 billion people around the world are affected by intermittent water supply (IWS), in which consumers are supplied with fewer than 24 hours/7 days per week of piped water supply (Bivins et al., 2017). Households lack continuous piped water service due to scheduled water rationing or insufficient water pressure. The number of people impacted by IWS is expected to increase with global urbanization trends (United Nations, Department of Economic and Social Affairs, Population Division, 2019; WHO \& UNICEF, 2015) while the average number of hours of piped municipal water supply available to urban households decreases (van den Berg \& Danilenko, 2010). This impact will likely be much greater in lowand middle-income countries, where IWS systems are especially common (van den Berg \& Danilenko, 2010). Water provided through IWS systems is often of worse quality than water provided by continuous water supply (CWS) systems (Coelho et al., 2003; Elala et al., 2011; Kumpel \& Nelson, 2016; Tokajian \& Hashwa, 2003). Bivins et al. estimate that IWS systems may be responsible for 17.2 million infections and cause 1560 deaths each year worldwide when compared to CWS systems (Bivins et al., 2017). Households have adapted to IWS systems in a variety of ways, including household water storage and diversifying water supply portfolios.

Households have invested in water storage for when piped water is unavailable including expensive underground cisterns, rooftop storage tanks, large buckets, or even an assortment of small storage vessels (Abubakar, 2018; Choe et al., 1996; Galaitsi et al., 2016; Guragai et al., 2017; Gurung et al., 2017; Majuru et al., 2016; Pattanayak et al., 2005; Vásquez, 2012; Zérah, 2000). Storage capacity varies widely, and is often correlated with household income: wealthier households tend to have larger, more permanent water storage while more socioeconomically disadvantaged households are often limited in storage capacity (Gulyani et al., 2005; Majuru et al., 2016; Pattanayak et al., 2005; Vásquez, 2012). Vásquez found that household storage investments in León, Nicaragua were primarily driven by households' perceptions of their water reliability, although home ownership and income were also significant 
(Vásquez, 2012). Although previous studies have shown storage to be ubiquitous in areas with IWS, its role in users' water access is not well understood.

In addition, water storage allows households access to multiple sources of water. Households often expend both time and money obtaining water from alternate sources such as water trucks, private wells or boreholes, bottled water, or rainwater (Majuru et al., 2016). Water delivered by tanker trucks has become a significant source of water in both Mexico City (Monserrat Iliana Gómez-Valdez et al., 2016; Kimmelman, 2017; Lerner et al., 2018; Tortajada, 2006) and other communities served by IWS worldwide (Fuentes-Galván et al., 2018; Galaitsi et al., 2016; Guragai et al., 2017; Gurung et al., 2017; Klassert et al., 2015; Londhe et al., 2004; Whittington et al., 1991; Zozmann et al., 2019). Water trucks deliver bulk volumes of water directly to residents' homes, often at a much higher cost than the municipal piped network. In Mexico City, there have been reports that trucked water deliveries may take up to 30 days and require residents to pay drivers a bribe (Kimmelman, 2017). Along with purchasing water in bulk, residents with IWS often purchase small volumes of purified, bottled water for drinking, since IWS water is often of poor quality (Coelho et al., 2003; Elala et al., 2011; Kumpel \& Nelson, 2016; Tokajian \& Hashwa, 2003).

Rainwater harvesting has recently been touted as a solution to Mexico City's water challenges (Chelleri et al., 2015; Garcia, 2016; Grabinsky, 2019; Valdez et al., 2016) and water scarcity in other cities (Campisano et al., 2017; Grant et al., 2013; Luthy et al., 2019; Yannopoulos et al., 2017) and can provide benefits at both the household and community level. Decentralized water sources like rainwater harvesting increase resilience and reliability of water supply at the household level (Chelleri et al., 2015). Rainwater harvesting gives households access to a low cost water source, although the financial viability of sophisticated rainwater collection systems at the household level has been contested (Concha Larrauri et al., 2019; Kumar, 2004; Rahman et al., 2007; Roebuck et al., 2011). At the community level, rainwater 
harvesting reduces stress on the centralized water system and provides conservation benefits in waterstressed areas where water supplies may otherwise come from an ancient aquifer or other non-renewable water source. Rainwater harvesting can delay the need for communities to build new infrastructure and may provide flood control (Campisano et al., 2017).

Adaptations to IWS, such as investing in storage or alternative water sources, place significant financial burdens on households. The additional costs incurred by households with IWS, often called "coping costs," often amount to a per-liter cost that is much more expensive than a household's bill for piped water (Majuru et al., 2016; Pattanayak et al., 2005; Zérah, 2000). Households with IWS also often incur time-related coping costs, since household members may need to spend time waiting for water service to fill storage containers, and may also need to spend time procuring alternative water sources, potentially forcing them to miss out on educational or employment opportunities outside of the home (Burt \& Isha, 2014; Majuru et al., 2016; Zérah, 2000). Since this burden falls disproportionately on women, IWS systems exacerbate inequities in household tasks (Majuru et al., 2016). The goal of a significant portion of previous work in IWS systems has been to estimate these coping costs and use them as a proxy for households' willingness-to-pay for improved piped water service (Majuru et al., 2016).

Previous research on household-level water use and consumption generally considers only a household's "primary" source of water rather than assessing all of a household's water sources together (Coulibaly et al., 2014; Elliott et al., 2017, 2019; WHO \& UNICEF, 2018). Even in previous research on IWS systems, where it has been demonstrated that households are likely to cope by using alternative sources of water and storage tanks, typically only the main piped source of water is examined. By limiting the focus to a single source of water, previous literature misses important nuances in water consumption patterns. For example, Andey and Kelkar (2009) use water meter data to explore changes in consumption of piped water in four Indian cities under intermittent water supply that then switched to continuous water supply 
without considering alternative water supply sources, such as water trucks, which have been shown to be of growing importance in the region (Londhe et al., 2004).

When households have multiple sources of water, the reliability of their water supply is dependent not only on the availability of the municipal water supply, but also on the cost and availability of other water sources and the household's decisions about managing their water storage and supply options (Galaitsi et al., 2016; Rosenberg et al., 2008). Therefore, representation of household water reliability requires representation of the human decision process for selecting and managing multiple water sources with alternative prices and availability (Shelton et al., 2018).

\section{Modeling IWS and Multiple Water Sources}

Previous models of IWS and multiple water source systems have been limited. Coulibaly et al. estimate water demand for a community in Jordan with multiple water sources using a combination of economic models: probability models to determine if a household will purchase a water source or not, and an Almost Ideal Demand System model to determine how much water they will purchase from each source. They found that demand for piped water becomes more elastic as water alternatives became available, signaling that the price of municipal piped water may be more price-constrained than previously thought (Coulibaly et al., 2014). Taylor et al. used customer demand satisfaction rate, source water availability, customer demand, and leakage to create an analytical model of the average behavior of an IWS system, calibrated with data from four actual distribution systems. Notably, their model did not consider water costs, unlike many other IWS models, but rather focused on water volume delivered. They found that satisfied customer demand was a local optimum for utilities, possibly explaining the persistence of these systems. They also suggest that demand satisfaction may be a useful metric for quantifying equity in IWS systems (Taylor et al., 2019). Baisa et al. attempted to quantify the social costs of water service uncertainty. They modeled water consumption for households in an IWS system in Mexico City assuming 
two water sources: IWS-constrained piped municipal water and an unlimited, expensive alternative (e.g. trucked water). In their model, households tailored their water consumption and usage to how much water they had available, resulting in misallocation of water supplies (e.g. one household in desperate need while a nearby household used water frivolously). Their results showed that many of the costs and inefficiencies from IWS can be eliminated by normalizing the piped water delivery schedule so all IWS households receive water at the same regular, equally-spaced intervals (Baisa et al., 2010). Rosenberg et al. (2007, 2008) modeled an IWS system in Amman, Jordan, using stochastic optimization, where costs are minimized for a set household water delivery. They identified household-level interventions (e.g. installing water-efficient appliances, fixing leaks, modifying water use behaviors, installing storage, etc) that were able to provide households with sufficient water supply at the lowest cost. Their results showed the importance of demand management and water conservation programs (Rosenberg et al., 2007, 2008).

All of these reviewed models relied on municipal piped water consumption data to simulate real households, data that is often lacking or incomplete in IWS systems. Additionally, all considered IWS communities in aggregate rather than assessing the interests of each individual household; the city-wide optimal solution is not necessarily the same as the household optimal. Finally, only Rosenberg et al. consider rainwater harvesting; the variability of rainwater availability means that water purchasing decisions must be dependent on the past rainfall and the household's capacity to store water, requiring daily decisions based on the state of the model. We develop a model that does not require previous household water purchasing data and instead only requires input data about the costs and volumes of water sources available to the household. Rather than aggregating water supply across an entire region, our model results show an individual household's economically optimal water purchasing decisions and investments. Additionally, we model rainwater harvesting and household water storage using a universal approximator (Radial Basis Function Networks) as a proxy for daily human decision making based on the current state of the system. 
Universal approximators can be used to approximate the outputs of any unknown function, given enough "training" data. They are stand-in functions that use given input/output training data to predict outputs (Cybenko, 1989). Radial Basis Function Networks (RBFNs) are a type of universal approximator based on an artificial neural network, where radial basis functions are used as the "hidden layer" activation functions. Radial basis functions are a class of function where the output is a function of the distance (radius) from a given point (center). The output decreases (or increases) monotonically based on the distance from the central point. The RBFN format provides more structure than a traditional artificial neural network by limiting model parameters to a radius around a constrained center point, giving a significant response only near the center point (Liao et al., 2003). They have been used widely in water resources predictive modeling to model flood forecasting, rainfall-runoff, and reservoir water quality (Jayawardena et al., 1997; Lin \& Chen, 2004; Tatar et al., 2015); in these cases, RBFNs require previous input/output data (e.g. past flood level, rainfall-runoff, or water quality data) to train the network. Recent applications have also demonstrated their efficacy in identifying optimal control policies - management decisions such as storage-release decisions (Giuliani et al., 2016). In these applications, the model is not trained on previous output data, but rather trained to find optimal outputs for the current state of the system. Universal approximators such as RBFNs are a flexible way to parameterize control policy for these multiobjective applications. Giuliani et al. (2014) demonstrated the utility of RBFNs in determining optimal reservoir releases. Quinn et al. (2017) applied RBFNs to identify pollution control policies for phosphorous release decisions in a shallow reservoir. These diverse applications demonstrate the versatility of RBFNs to use information on the state of a system (e.g. water level in storage tank) to determine an output decision (e.g. buying trucked water).

The objective of this study was to determine the implications of household-level investments (e.g. rainwater harvesting, storage tank size) on water supply reliability for households with IWS. We develop a novel model of household-scale water management that can be generalized to investigate household 
water supply reliability and coping costs for households with IWS that use multiple water sources. To accomplish this, we used a novel method of RBFNs as a proxy for human decision making. Using this approach, we determine optimal water purchasing and storage investments for households in Mexico City. Interviews were conducted with households in areas of the city with IWS to identify a range of water source availabilities and to ensure the model can accurately represent reality for households.

\section{Materials and Methods}

\section{Study Site}

The Mexico City Metropolitan Area (MCMA) is home to more than 20 million people as of 2018 (United Nations, 2019). Less than 30\% of MCMA residents receive continuous piped water service (Sistema de Aguas de la Ciudad de Mexico (SACMEX), 2014); the remaining households are supplied with IWS. Municipal water is usually delivered based on a weekly schedule (tandeo), however deliveries in some parts of the city may be erratic (Baisa et al., 2010). Households in the MCMA have various types of water storage containers at their homes to store water for household uses (e.g. laundry, sanitation) for periods when piped municipal water is unavailable, including cisterns (underground tanks, typically 1000 liters or more), tinacos (smaller tanks, typically on rooftops and around 500-1100 liters), tambos (plastic drums, typically 100-200 liters), and/or large buckets (Monserrat I. Gómez-Valdez et al., 2015). In addition to helping residents cope with unreliable piped water deliveries, household storage also provides residents with alternative water options, including ordering bulk water from water trucks (pipas), capturing rainwater, or drawing water from springs or shallow groundwater (Tortajada, 2006). Water trucks may be either supplied by the city (public pipas) or owned by private companies for profit (private pipas). Private pipas are much more expensive than the piped water network. Public pipas are free but may require long wait times or bribing a water truck driver (Kimmelman, 2017). The majority of residents of the MCMA rely on bottled or filtered water for drinking due to widespread perception that the municipal piped system 
is unsafe to drink (Espinosa-García et al., 2015; Inter-American Development Bank (IDB), 2011;

Tortajada, 2006). Households typically purchase and store this purified water separately from bulk water supplies in 20-liter jugs (garrafones) or individual water bottles (Inter-American Development Bank (IDB), 2011).

\section{Household Water Management Model}

\section{Simulation Model.}

The goal of the model is to represent water purchasing, storage, and consumption for an arbitrary household in Mexico City. This is accomplished via multi-objective optimization using a RBFN. The simulation model uses RBFN decisions and other inputs to output the optimization objectives: cost and reliability (Figure 1).

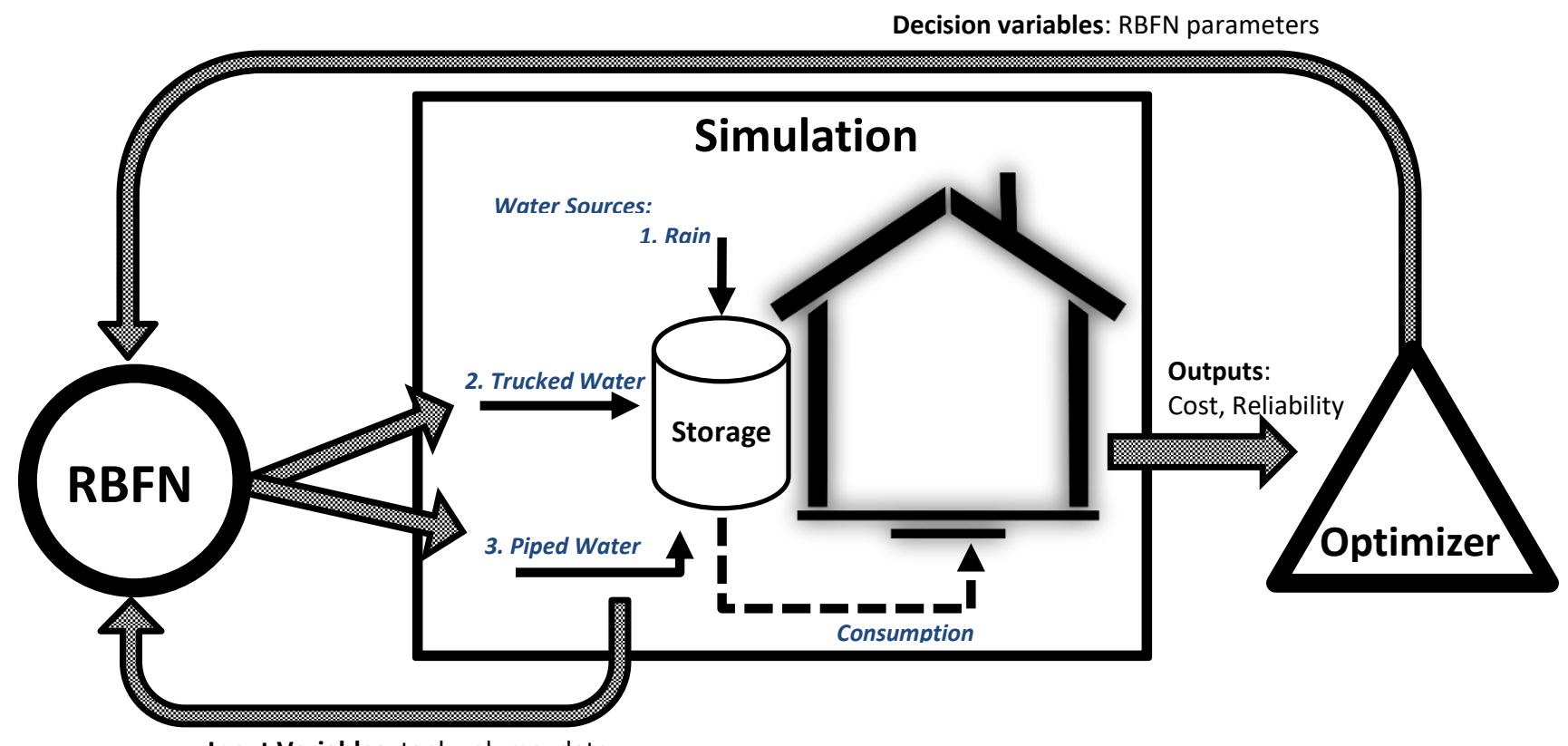

Input Variables: tank volume, date

Figure 1. Model schematic. A multi-year simulation uses RBFNs to make daily decisions regarding volume of water to purchase from trucks and the piped network based on the current state of the simulation model. These water volumes, along with rainwater, are modeled as storage. Consumption and spill are accounted for. The simulation model determines total costs and reliability which become objectives in the optimization. The optimization model decision variables are the RBFN parameters. The final model (after optimization) represents a household making optimal purchasing and storage decisions. 
In the simulation model, the RBFN decisions are constrained by the availability of piped municipal water according to the household's IWS schedule and the minimum required trucked-water delivery (the minimum volume of piped water that must be purchased in order for the truck driver to make the delivery). We calculated the volume of rainwater harvested using roof area and a standard loss factor (Abdulla \& Al-Shareef, 2009). The household's daily consumption is either the target consumption (if sufficient water is available), or else the remaining stored water. The total volume of water that can be stored at one time is constrained by the household's storage tank size; any excess water is subtracted as a spill factor. The simulation model is run for the life expectancy of a storage tank, which is estimated to be twelve years (Inter-American Development Bank (IDB), 2011). The full details of the simulation model can be found in the Supporting Information.

The household water context in the MCMA is complex and nuanced (Romero Lankao, 2010; Tortajada, 2006) so simplifications were introduced to create this model. We consider only three water sources: piped water, trucked water from privately owned pipas, and rainwater. Piped water was chosen since it was the most common water source. Although use of city-supplied public water trucks is common, this source was neglected since its main costs are time-related costs and this model considered only financial costs; therefore, trucked water from privately owned trucks were used to represent all trucked water. Finally, rainwater, while not a common water source, was included as it has been touted as an important part of Mexico City's water future (Chelleri et al., 2015; Garcia, 2016; Grabinsky, 2019; Valdez et al., 2016). Bottled and filtered water were not modeled, since they are stored separately from the other water sources (i.e., not in a bulk storage tank). Although households may have multiple water storage tanks for different types of water, we modeled only total storage volume (assuming all water sources are stored together).

Optimization Model: Management Objectives. 
The simulation model of the household provides the optimization with its objectives: to maximize reliability of water supply and minimize cost (Equation 1).

$$
\text { Objective }=\operatorname{Min}(\text { Cost },(1-\text { Reliability }))
$$

Reliability is defined as the probability that the system is in a satisfactory state (Hashimoto et al., 1982). Here, the satisfactory state is when the daily household consumption target is met (Equation 2). Since the optimization was a minimization, we used unreliability as the objective.

$$
\text { Reliability }=\operatorname{Prob}\left(V^{\text {target }} \leq V^{\text {consume }}\right)
$$

In this equation, the household consumption target volume $\left(V^{\text {target }}\right)$ is the product of the household size and per capita consumption, while $V^{\text {consume }}$ is the volume of water that is actually consumed that day.

The second objective, cost, is equal to the net present value of annual costs associated with each water source and the infrastructure investments for the household (piped water, trucked water, tank investment, and rainwater harvesting investment) summed over the length of the simulation (Equation 3)

$$
\operatorname{Cost}=\sum_{y=1}^{L} \frac{V_{\text {muni, }, * C_{\text {muni }}}}{(1+D)^{y}}+\frac{V_{\text {truck }, y^{*} C_{\text {truck }}}}{(1+D)^{y}}+\frac{\frac{C_{\text {tank }}}{L_{\text {tank }}}+C M_{\text {tank }}}{(1+D)^{y}}+\frac{\frac{C_{\text {rain }}}{L_{\text {rain }}+C M_{\text {rain }}}}{(1+D)^{y}}
$$

where $D$ is the discounting rate; $V_{\text {muni,y }}$ is the total volume of piped municipal water for year $y$ as determined by the RBFN decision; $C_{\text {muni,y }}$ is the per-liter cost of city water; $V_{\text {truck,y }}$ is the RBFNdetermined volume of water supplied from water trucks for year $y$; $C_{\text {truck }}$ is the cost per liter of truckedwater; $C_{\text {rain }}$ is the cost of a rainwater harvesting system investment; $L_{\text {tank }}$ is the expected lifespan of the storage tank; $L_{\text {rain }}$ is the expected lifespan of the rainwater harvesting system; $C M_{\text {tank }}$ is the annual tank maintenance cost; and $C M_{\text {rain }}$ is the annual rainwater harvesting system maintenance cost. $C_{\text {tank }}$, the cost 
of a water storage tank investment (Equation 4) was derived as a linear function using observed tank volume $\left(V_{\text {tank }}\right)$ cost data from Mexico City (Isla Urbana, n.d.).

$$
C_{\text {tank }}=2.0621 * V_{\text {tank }}
$$

\section{RBFN Model: Water Supply Decisions.}

Our model uses two RBFNs: one to determine the volume of water to purchase from the piped municipal system and one to determine the volume from trucked water. Both decisions are based on the current state of the model (i.e. current volume of water stored, day of the week relative to IWS schedule, and day of the year to account for rainfall seasonality).

Equation 5 shows the decision equation (RBFN) as a function of the sum of the individual radial basis functions (RBFs), where $u_{t}^{k}$ is the output decision (the volume of water purchased from water source $k$ on day $t$ ) and $N$ is the number of radial basis functions, $\phi_{i}\left(X_{t}\right)$. The weight of each RBF, $w_{i, k}$ determines its importance in the overall decision. Each decision function contains $N$ number of RBFs. The weight of each RBF determines its importance in the overall decision. Weights must be positive and sum to one (Giuliani et al., 2014).

$$
u_{t}^{k}=\sum_{i=1}^{N} w_{i, k} \varphi_{i}\left(X_{t}\right)
$$

Equation 6 is the actual RBF, here we use a Gaussian function where $M$ is the number of input variables $X_{t}$. For each input variable $c_{i, j}$ represents the center of the function, constrained by $c_{i} \in[-1,1]$, and $b_{e, j}$ represents the radius, constrained by $b_{i} \in(0,1]$ (Giuliani et al., 2014).

$$
\varphi_{i}\left(X_{t}\right)=\exp \left[-\sum_{j=1}^{M} \frac{\left(\left(X_{t}\right)_{j}-c_{i, j}\right)^{2}}{b_{j, i}^{2}}\right]
$$


Each of the RBFNs in our model contains two radial basis functions; we found that two functions were sufficient to determine optimal purchases and limiting the RBFNs to two functions reduced the number of decision variables and the computation time. The RBFN decisions are based on four input variables $\left(X_{t}\right)$ : current volume of stored water, day of the week relative to IWS schedule, $\sin (2 \pi \mathrm{T} / 365)$, and $\cos (2 \pi \mathrm{T} / 365)$ where $\mathrm{T}$ is the numerical day of the year. These last two are a method of representing seasonality (Pianosi et al., 2011), a critical factor to include since rainfall in Mexico is highly seasonal.

The decision variables for the optimization model are the parameters of the RBFNs ( $w_{i, k}$ for each RBF, and $c_{i, j}$ and $b_{e, j}$ for every input variable in every RBF for a total of 36 decision variables). Additionally, storage tank size is included as a decision variable in some runs of the model (total of 37 decision variables) so that the models output the optimal storage tank size.

RBFNs were trained over a 12-year simulation period using historical rainfall data for a gauge in Iztapalapa from 2006-2017 from Mexico City's water utility, SACMEX (Sistema de Aguas de la Ciudad de México). The Borg multi-objective evolutionary algorithm (Hadka \& Reed, 2013) was used to identify approximate Pareto-optimal (non-dominated) solutions.

\section{Model Construction through Household interviews}

The model was informed by interviews with households in the MCMA. Responses were compared to input variable assumptions and used to confirm that the household model was able to accurately represent real-world situations in the MCMA. Between March and April 2019, we conducted sixteen semistructured interviews in three municipalities of the region - Álvaro Obregón, Iztapalapa, and Tláhuac - to elicit information on household demographics, water services, and household water infrastructure (Figure 2). All participants in this study were adults over the age of 18 who lived in the selected municipalities for at least two years. We obtained informed consent from all participants (the study protocol was approved by the University of Massachusetts Amherst Institutional Review Board (IRB)). 


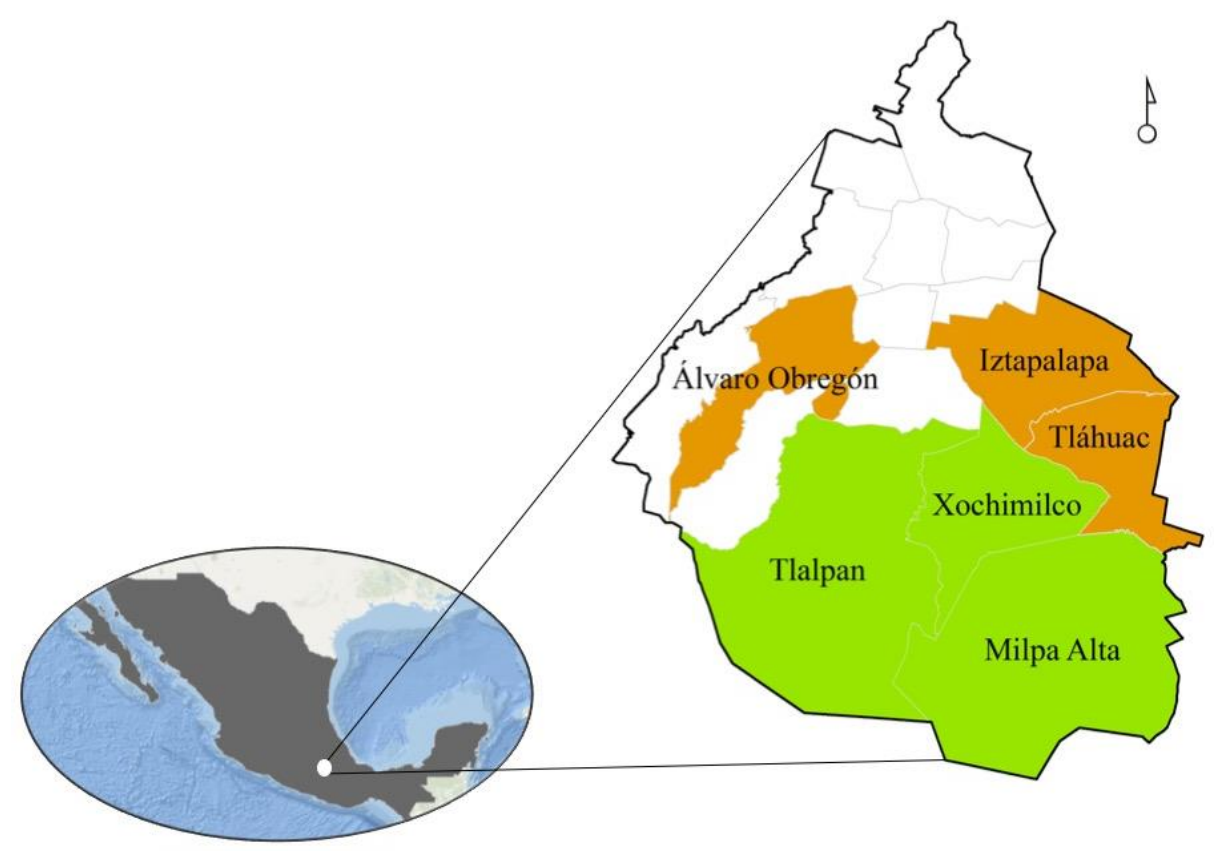

Figure 2. Location of the study municipalities - Álvaro Obregón, Iztapalapa, and Tláhuac - shown in orange within the MCMA region. Other municipalities considered for the study shown in green (shapefile courtesy SACMEX).

In pilot work and over the course of fieldwork, we developed a preliminary typology of water access (Kumpel et al., 2017) that grouped households according to their available water sources: 1) Piped water (piped municipal water is both accessible to the household and is their main source of water); 2) both piped and trucked water (piped water is accessible to the household, but they regularly use trucked water as well); 3) exclusively trucked water (piped water is not accessible to the household and they rely entirely on trucked water); and 4) households that lacked regular access to both piped and trucked water, but obtained these water sources by proxy. Households were recruited from each of the water access types to interview. The sample was not designed to be representative, but rather was intended to capture a range of household experiences with water supplies and water-related infrastructure. Notably, water supply varies throughout the year and therefore the timing of interviews affected how households were classified (i.e., households might belong to a one type during the dry season and another during the rainy season); 
therefore, these classifications represent the situation that existed at the end of the dry winter season (in late March/early April) at time of the interviews.

Service areas for household interviews were selected based on communication with local organizations and trucked water filling points (garzas) to understand services areas for network and trucked water. The second house on the street in a selected service area was approached. If that household was ineligible or refused to participate, we continued up the street until an eligible and willing household was recruited.

\section{Sensitivity Analysis}

A one-at-a-time (local) sensitivity analysis was performed on the model to determine which variables have the greatest effect on annual household costs. "Low" and "high" values were derived from both literature and interview results (Table 1). One variable at a time was changed to its extreme value while all other variables remain at their original value. The reliability was fixed so the model could output a single numerical value (annual household cost) to facilitate comparisons between low/high ranges. While this approach does not explicitly capture interactive effects between variables, it is useful for initial screening of their relative importance. These results were used to identify variables to study in more depth and the factors most affecting household costs.

Table 1. Variable names and descriptions. Values are given for the original model (with data sources referenced), interview results, and sensitivity analysis high/low ranges.

\begin{tabular}{|c|c|c|c|c|}
\hline $\begin{array}{l}\text { Variable } \\
\text { Name }\end{array}$ & Variable Description & $\begin{array}{l}\text { Original Model } \\
\text { Value }\end{array}$ & $\begin{array}{l}\text { Sensitivity } \\
\text { Analysis Low } \\
\text { Value }\end{array}$ & $\begin{array}{l}\text { Sensitivity } \\
\text { Analysis High } \\
\text { Value }\end{array}$ \\
\hline$C_{\text {Truck }}$ & $\begin{array}{l}\text { Per liter cost of Truck } \\
\text { Water }\end{array}$ & $\begin{array}{l}\$ 0.25 \mathrm{MXN} / \text { liter (St. } \\
\text { George Freeman et } \\
\text { al., 2020) }\end{array}$ & $\begin{array}{l}\$ 0.05 \\
\text { MXN/liter }\end{array}$ & $\begin{array}{l}\$ 0.80 \\
\text { MXN/liter }\end{array}$ \\
\hline$C_{M \text { unicipal }}$ & $\begin{array}{l}\text { Per liter cost of } \\
\text { Municipal Water }\end{array}$ & $\begin{array}{l}\text { \$0.05 } \\
\text { MXN/liter(Sistema } \\
\text { de Aguas de la } \\
\text { Ciudad de Mexico } \\
\text { (SACMEX), 2017) }\end{array}$ & $\begin{array}{l}\$ 0.003 \\
\text { MXN/liter }\end{array}$ & $\begin{array}{l}\$ 0.09 \\
\text { MXN/liter }\end{array}$ \\
\hline$C_{\text {Rain }}$ & $\begin{array}{l}\text { Cost of Rainwater } \\
\text { Harvesting System }\end{array}$ & $\begin{array}{l}\$ 8800 \mathrm{MXN}(I s / a \\
\text { Urbana, n.d.) }\end{array}$ & $\$ 100 \mathrm{MXN}$ & $\$ 12900 \mathrm{MXN}$ \\
\hline
\end{tabular}




\begin{tabular}{|c|c|c|c|c|}
\hline$C M_{\text {tank }}$ & $\begin{array}{l}\text { Annual Tank } \\
\text { Maintenance Cost }\end{array}$ & $\begin{array}{l}\text { \$88 MXN (Inter- } \\
\text { American } \\
\text { Development Bank } \\
\text { (IDB), 2011) }\end{array}$ & NA & NA \\
\hline$C M_{\text {rain }}$ & $\begin{array}{l}\text { Annual Rainwater } \\
\text { Maintenance Cost }\end{array}$ & $\begin{array}{l}\text { \$8 MXN (Inter- } \\
\text { American } \\
\text { Development Bank } \\
\text { (IDB), 2011) }\end{array}$ & NA & NA \\
\hline$L_{\text {tank }}$ & $\begin{array}{l}\text { Storage Tank } \\
\text { Expected Lifespan }\end{array}$ & $\begin{array}{l}12 \text { years (Inter- } \\
\text { American } \\
\text { Development Bank } \\
\text { (IDB), 2011) }\end{array}$ & NA & NA \\
\hline Lrain & $\begin{array}{l}\text { Rainwater } \\
\text { Harvesting Expected } \\
\text { Lifespan }\end{array}$ & $\begin{array}{l}12 \text { years (Inter- } \\
\text { American } \\
\text { Development Bank } \\
\text { (IDB), 2011) }\end{array}$ & NA & NA \\
\hline$D$ & Discounting Rate & $\begin{array}{l}0.1 \text { (Coppola et al., } \\
2014 \text { ) }\end{array}$ & 0.15 & 0.05 \\
\hline$D_{\text {rain }}$ & Depth of rainfall & $\begin{array}{l}\text { SACMEX Rain } \\
\text { Gauge Data }\end{array}$ & $+20 \%$ & $-20 \%$ \\
\hline$A$ & $\begin{array}{l}\text { Rainwater Collection } \\
\text { Area }\end{array}$ & $\begin{array}{l}75 \mathrm{~m}^{2} \text { (Google \& } \\
\text { Instituto Nacional } \\
\text { de Estadistica y } \\
\text { Geografia (INEGI), } \\
\text { 2018) }\end{array}$ & $\begin{array}{l}30 \mathrm{~m}^{2} \\
\text { (Marosi, } \\
2017 \text { ) }\end{array}$ & $\begin{array}{l}500 \mathrm{~m}^{2} \\
\text { (Concha } \\
\text { Larrauri et } \\
\text { al., 2019) }\end{array}$ \\
\hline$L F$ & $\begin{array}{l}\text { Fraction of rainwater } \\
\text { lost to collection } \\
\text { inefficiencies }\end{array}$ & $\begin{array}{l}20 \% \text { (Abdulla \& Al- } \\
\text { Shareef, 2009) }\end{array}$ & NA & NA \\
\hline$P$ & Household Size & $\begin{array}{l}.4 \\
\text { people/household } \\
\text { (INEGI, n.d.) }\end{array}$ & 1 & 10 \\
\hline Vconsume & Water Consumption & $\begin{array}{l}110 \\
\text { liters/person/day } \\
\text { (INEGI, n.d.) }\end{array}$ & 15 & 380 \\
\hline$V_{\text {tank }}$ & $\begin{array}{l}\text { Volume of water } \\
\text { storage }\end{array}$ & Output, or $2500 \mathrm{~L}$ & $500 \mathrm{~L}$ & $5000 \mathrm{~L}$ \\
\hline Lim $^{\text {truck }}$ & $\begin{array}{l}\text { Minimum volume of } \\
\text { water delivered by } \\
\text { pipa }\end{array}$ & $200 \mathrm{~L}$ & $50 \mathrm{~L}$ & $2500 \mathrm{~L}$ \\
\hline$R$ & $\begin{array}{l}\text { Flowrate of } \\
\text { Municipal water }\end{array}$ & $500 \mathrm{~L} /$ hour & $250 \mathrm{~L}$ & $1000 \mathrm{~L}$ \\
\hline
\end{tabular}

\section{Model Scenarios}

\section{Varying IWS Schedules and Household Water Infrastructure Investments}

The model produces the set of optimal (i.e. non-dominated) household water purchasing policies which maximize reliability while minimizing costs. We ran the model for various piped municipal water supply scenarios to compare households with different water situations. The scenarios shown in Table 2 were 
selected based on typical household IWS schedules in Mexico City (Sistema de Aguas de la Ciudad de Mexico (SACMEX), 2006) and insights from the household interviews.

Table 2. Municipal Piped Water Supply Scenarios

\begin{tabular}{|c|c|}
\hline Name & \multicolumn{1}{|c|}{ Description } \\
\hline $\begin{array}{c}\text { Continuous Water } \\
\text { Medium IWS Schedule }\end{array}$ & 24 hours of piped water, 7 days/week \\
\hline Low IWS Schedule & $\begin{array}{l}\text { 4 hours of piped water, 1 scheduled } \\
\text { day/week }\end{array}$ \\
\hline No Piped Supply & No piped water is available \\
\hline Random IWS Supply & $\begin{array}{l}\text { 4 hours of piped water is delivered on one } \\
\text { random day per week. Water delivery day is } \\
\text { random for each model run. }\end{array}$ \\
\hline Split IWS Supply & $\begin{array}{l}\text { 12 hours of piped water is delivered on two } \\
\text { non-consecutive days: 6 hours on Monday, } 6 \\
\text { hours on Thursday. }\end{array}$ \\
\hline
\end{tabular}

By targeting a reliability of $95 \%$ for each scenario, we can see the daily and seasonal breakdown of water sources output from the model and compare them to the household interview results. Costs at $95 \%$ reliability were modeled for the entire range of IWS schedules (from 2 hours/week to 168 hours/week) both with and without rainwater harvesting to explore how costs were affected by varying hours of piped supply, and to find IWS schedules where rainwater harvesting is optimal. Finally, we explore what factors drive model behavior. The one-at-a-time (local) sensitivity analysis was used to determine the factors that most affected coping costs, significant factors were explored in more detail. These tests provided insights into the role that individual households play in safeguarding their own water supply. Based on these results, household storage volume was explored in more detail.

\section{Results and Discussion}

\section{Optimal household water storage and supply portfolios.}


The Pareto front, which shows the set of non-dominated (optimal) solutions for modeled household water portfolios, demonstrates the trade-offs between annual household water costs and reliability of water supply. Logically, increased reliability is associated with increased cost across all water supply scenarios (Figure 3a). Daily volumes purchased from each water source for the Pareto-optimal solution where households experience a 95\% reliability provide more insight into each scenario (Figure 3b-f). The continuous water supply (CWS) scenario and medium IWS scenario (12 hours of piped supply per week) have similar household cost/reliability trade-off curves: the medium IWS scenario is only slightly more expensive than CWS scenario, even though water is available only once per week. Households with CWS would purchase municipal piped water and collect rainwater (Figure 3b). Under the medium-supply scenario, households can still rely on only municipal-piped water and rainwater by investing in a sufficiently large storage tank to store enough piped water to last through the week, rather than purchasing trucked water (Figure 3c). Since the division of water sources remains the same as the CWS model under this scenario, the only additional cost to the household is a larger, more expensive storage tank.

The curve for the low IWS scenario (4 hours of piped supply per week) is similar to the previous two until a reliability of $90 \%$. At this point, the piped/rain water is insufficient and additional water must be purchased from water trucks to meet consumption needs, driving up costs considerably (Figure 3d). These results demonstrate that, as long as a sufficient total volume of piped water is delivered throughout the week, households can negate the coping costs of IWS by purchasing a larger storage tank; it is only when the total volume of piped water delivered per week is insufficient to meet a household's total weekly needs that annual water costs increase drastically (Figure 4). This "sufficient" volume of water is around five hours of supply per week for an average sized household. Furthermore, when piped water delivery days are randomized (4 hours delivered on one random day per week), cost/reliability trade-off curve is not significantly affected (Figure 3e); household storage is able to compensate for uncertainty in 
deliveries. The no-piped-water scenario is much more expensive than any other scenarios since households must purchase much more trucked water (Figure 3f).
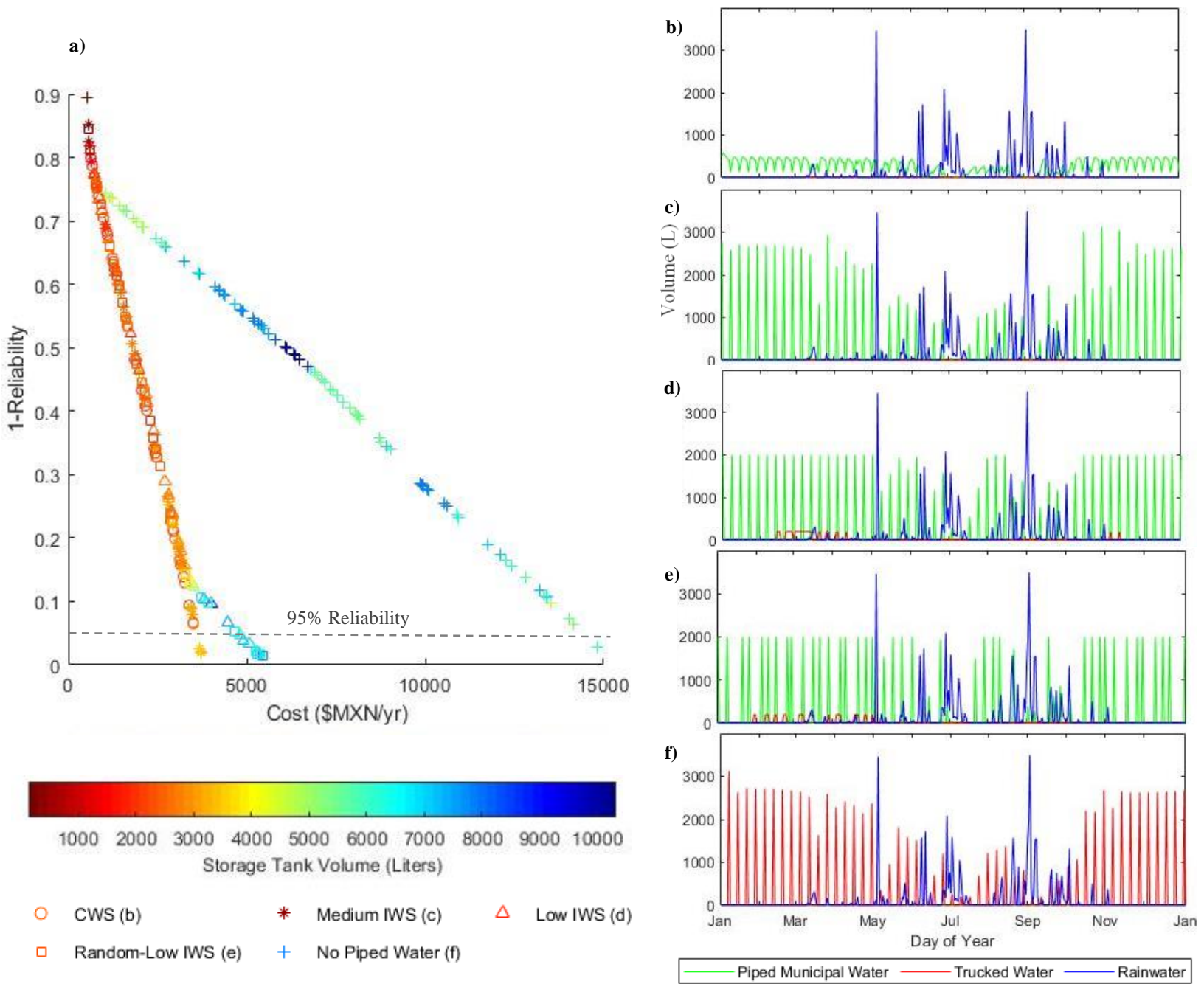

Figure 3. Household cost and reliability trade-off and optimal tank size for various scenarios a) Pareto fronts for various piped municipal water supply scenarios. Symbol shapes represent the different piped water supply scenarios and colors represent the optimal storage tank volume. Volume (L) obtained from each water source on each day throughout the year to achieve 95\% Reliability for: b) Continuous Water Supply (CWS); c) Medium IWS (12 hours per week); d) Low IWS (4 hours per week); e) Random Low IWS (4 hours delivered on one random day per week); f) No municipal piped water available. 

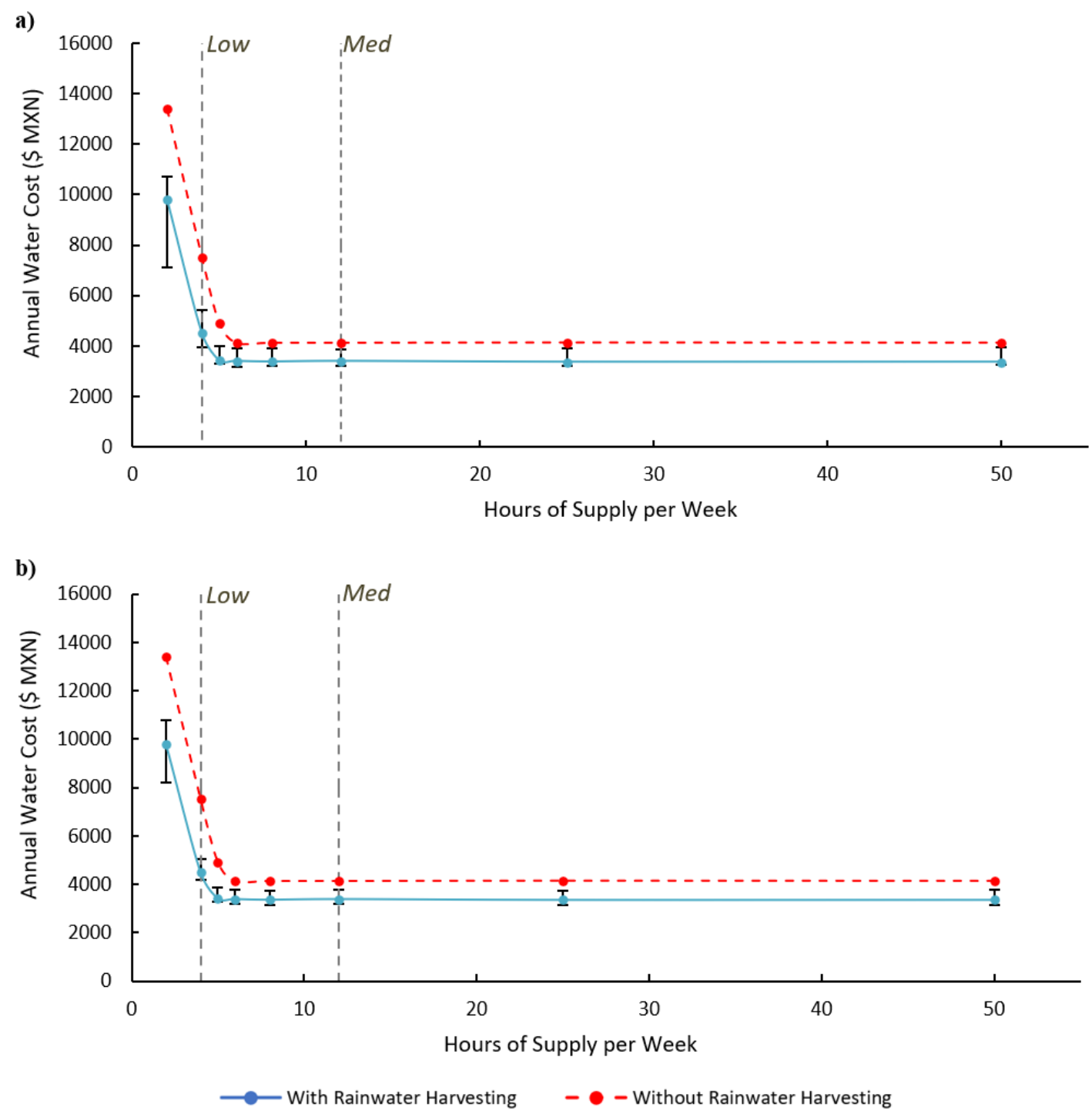

Figure 4. Annual cost of water supply for reliability of $95 \%$ at varying hours of municipal piped water supply. The low- and medium- IWS and CWS scenarios are marked on the graph with dashed lines. Costs for both with and without rainwater harvesting are included. The $\mathrm{x}$-axis is truncated at 50 hours/week for clarify, but the costs are flat until the 168 hours/week (i.e. CWS). Error bars on Rainwater Harvesting data indicate a) the range of values for different rain gauges across Mexico City; b) range of values for different years of rainfall data.

Seasonality and Rainwater Harvesting. Optimal water sources vary seasonally. During the rainy summer season, half of a household's water needs could be supplied by rainwater. Under all three IWS scenarios considered, the other half can be met with piped municipal water (Figure 5a, c). However, rainwater can only supply about $5 \%$ of a household's water during the drier winter months, most of which 
comes from late spring or early fall rains on the edges of the rainy season. Households with CWS or a medium IWS schedule can supply the remainder of their water needs with piped municipal water (Figure 5b). However, households with low IWS (Figure 5c) require trucked water to meet the remaining water needs during the dry winter months. Households with no access to piped water (Figure 5d) may be able to rely more on rainwater during the summer months than those with IWS since their optimal storage tank is slightly larger. Additionally, trucked water in this model is assumed to be available whenever and wherever it is needed, so these households may have more space in their storage tank for rainwater than IWS households that must use much of their storage for their piped water delivery

a)

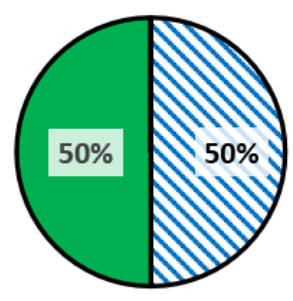

Summer

c)

Random-Low IWS

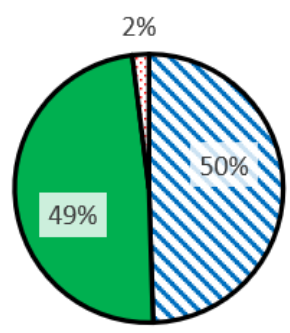

Summer
CWS

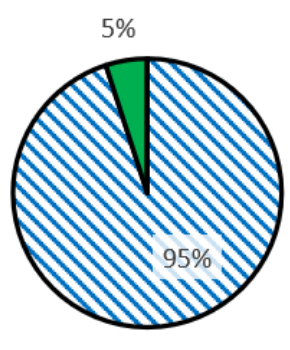

Winter b)

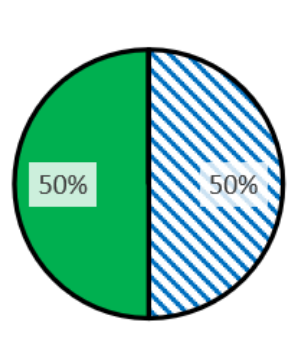

Summer

Low IWS

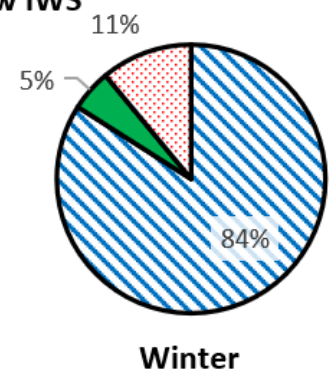

d) No Piped Water

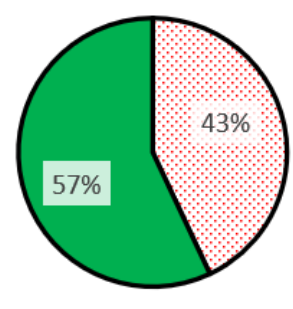

Summer

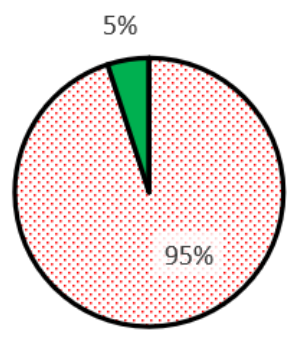

Winter

$\mathbb{Q}$ Piped-City $\square$ Rain $\square$ Truck

Figure 5. Fraction of water provided by each source calculated for each scenario at $95 \%$ reliability for both summer (May-October) and winter (November-April) for four water-supply scenarios: a) CWS; b) Low Intermittent Supply Schedule; c) Randomized-Low IWS schedule; and d) No piped water scenario. 
The model demonstrates that rainwater harvesting is economically optimal for every piped water supply schedule, including CWS (Table 3). This is especially significant since the model accounts for the costs of both the rainwater harvesting system investment and maintenance, and the increased cost of a larger storage tank. The cost savings are especially large for low IWS schedules where rainwater replaces more expensive trucked water (Figure 4). Although cost savings from rainwater harvesting vary in different parts of the city (Figure 4a) and throughout the years (Figure 4b) due to spatial and temporal rainfall variation, especially for low IWS scenarios, the annual water costs are always lower than the nonrainwater harvesting scenarios.

Table 3. Average annual water costs for households with and without rainwater harvesting for three piped water supply schedules.

\begin{tabular}{|c|c|c|c|}
\hline Schedule & $\begin{array}{c}\text { With } \\
\text { Rainwater } \\
\text { Harvesting } \\
\text { (\$ MXN) }\end{array}$ & $\begin{array}{c}\text { Without } \\
\text { Rainwater } \\
\text { Harvesting } \\
\text { (\$ MXN) }\end{array}$ & $\begin{array}{c}\text { Rainwater } \\
\text { Harvesting } \\
\text { Savings }\end{array}$ \\
\hline CWS & 3350 & 3957 & 607 \\
\hline Medium & 3391 & 4123 & 732 \\
\hline Low & 4497 & 7521 & 3024 \\
\hline
\end{tabular}

Notably, rainwater harvesting may provide many community-wide benefits, such as decreased pressure on strained water supplies and flood mitigation potential (Chelleri et al., 2015; Grant et al., 2013; Luthy et al., 2019; Valdez et al., 2016) that are not considered in this model. However, the seasonal breakdown of water sources (Figure 5) demonstrates that even during the rainy summer season, rainwater can only meet about half of the average household's needs (assuming a collection area of $75 \mathrm{~m}^{2}$ ), and during the winter, rainfall is virtually nonexistent. Therefore, although rainwater harvesting may save a household money and provide community-wide benefits, it must be part of a larger water resources plan. The rainwater in this model can also be used as a proxy for other water sources that require an initial investment but then 
provide "free" water, such as water from springs or wells. These options are not as common in Mexico City, but are important water sources in other IWS communities (Majuru et al., 2016).

\section{Household Interviews: Sources and Storage}

The sixteen interviewed households reported using water sources generally in-line with the model structure: piped municipal water, trucked water (from private or publicly owned trucks), and rainwater. Households also purchased bottled or filtered water separately for drinking. Households with CWS (or sufficient IWS that were able to rely primarily on piped water) did not usually receive trucked water on a regular basis, although they did report occasionally purchasing trucked water during extreme events that interrupted piped water service, such as the earthquake in 2017. While piped, bottled, and filtered water were accessed year-round, households that used trucked water regularly often did so only for a few months during the dry season, a choice consistent with model results. More households in our sample than expected (5 of 16), reported using rainwater, primarily for cleaning or other hygiene-related activities. However, only one household had a formal rainwater harvesting system like that modeled here; most households collected rainwater in buckets. Use of rainwater was reported only for two to three months of the year during the rainy season, consistent with model results.

The small scope and aim of the field data collection means the percentages of households that rely on each water source is not meant to be representative of the MCMA population, but rather to gain understanding of experiences with water supply and infrastructure to inform the model (Table 4). Surveybased methods of measuring household water use are often inaccurate (Apoorva et al., 2018; Kumpel et al., 2017; Wutich, 2009) as households - particularly those with more continuous piped supply - often did not know the volume of water purchased from each source. Households with IWS were able to estimate the frequency that piped water was available to them and the volume they collected each time. 
Of the fourteen households with some piped water supply, only five households paid bills based on a metered rate; two households were on a fixed monthly rate, and seven households received a waiver of payment or had irregular connections. Households reported that purchasing trucked water was significantly more expensive than the piped municipal water rate, although only one household was able to estimate their piped metered rate. Filtered and bottled water were significantly more expensive than other sources but were purchased in much smaller volumes since they were reportedly used almost exclusively for drinking and cooking and were not stored with the other water sources. While households did not report that rainwater incurred expenditures per liter, it did require investment and maintenance in a collection system, although few households were able to remember how much they spent on this. Households often stored rainwater separately from other water sources and reported using it for different purposes, although our model groups all storage together. One household with a formal rainwater collection system had had their system installed for free. Our model does not account for waived water fees or free rainwater harvesting systems and instead assumes that households must pay for all water sources and investments. However, at a system-wide level, water sources and investments that are subsidized must still be paid for by the society collectively, even if the cost burden is removed from the individual household.

Households used a variety of infrastructure to store and transport their water (Table 3), often using more than one type of tank to store water. Many households shared at least one water tank with their neighbors, especially the larger and more expensive cisterns (notably different than our model's assumptions) On average, the total storage volume that households reported having access to was 2300 liters (similar to the model's optimal storage tank volume) although reported values ranged from 200 liters to 8,000 liters. 
Table 4. Summary of results of household interviews. Fraction of respondents using, average monthly volumes, and average costs of each water source are reported (top). Fraction of households using each type of storage infrastructure, average capacity, and costs (bottom). "n" reports number of interviewed households reporting data.

\begin{tabular}{|c|c|c|c|c|c|c|}
\hline \multirow[b]{2}{*}{ Water Source } & \multirow{2}{*}{$\begin{array}{c}\begin{array}{c}\text { \% of households } \\
\text { using: }\end{array} \\
\text { Water source } \\
\text { regularly / sometimes }\end{array}$} & \multicolumn{2}{|c|}{ Volume (L) } & \multicolumn{3}{|c|}{ Costs (\$MEX) } \\
\hline & & $\begin{array}{l}\text { per household } \\
\text { per month }\end{array}$ & & Per liter & $\begin{array}{l}\text { Additional cost per } \\
\text { delivery or } \\
\text { collection }(\$ M X N)\end{array}$ & \\
\hline Piped & $88 \%$ & $6017(n=3)$ & & $0.006(n=1)$ & NA & \\
\hline $\begin{array}{l}\text { City-supplied Truck } \\
\text { Water }\end{array}$ & $12 \% / 25 \%$ & $8350(n=3)$ & & Free source & $\$ 0.83(n=6)$ & \\
\hline $\begin{array}{l}\text { Privately-owned } \\
\text { Truck Water }\end{array}$ & $6 \% / 19 \%$ & $3373(n=3)$ & & $0.36(n=3)$ & None reported & \\
\hline Bottled & $25 \%$ & $53(n=4)$ & & $4.38(n=4)$ & $0 \min (n=4)$ & \\
\hline Filtered & $88 \%$ & $351(n=14)$ & & $0.72(n=13)$ & $2.14 \min (n=14)$ & \\
\hline Rainwater & $31 \%$ & $8275(n=2)$ & & Free source & None reported & \\
\hline Spring & NA\% / NA\% & NA & & Free source & None reported & \\
\hline Other & $12 \%$ & NA & & NA & - & \\
\hline Infrastructure & Storage & $\begin{array}{c}\text { Capacity per } \\
\text { tank }\end{array}$ & $\begin{array}{c}\text { Capacity per } \\
\text { household }^{\text {a }}\end{array}$ & Purchase Cost & Installation & $\begin{array}{c}\text { Annual } \\
\text { maintenance }\end{array}$ \\
\hline Cistern & $44 \%$ & $4000(n=6)$ & $2958(n=6)$ & $8333(n=3)$ & None reported & $52.1(n=7)$ \\
\hline Tinaco & $75 \%$ & $1496(n=12)$ & $1031(n=12)$ & $1475(n=4)$ & $767(n=3)$ & $25(n=10)$ \\
\hline Tambo & $62 \%$ & $294(n=10)$ & $259(n=10)$ & $173(n=7)$ & None reported & $90.8(n=6)$ \\
\hline Bottle & $94 \%$ & $69(n=14)$ & - & $53(n=11)$ & None reported & Not Relevant \\
\hline Pump & $44 \%$ & $1(n=5)$ & - & $1700(n=4)$ & None reported & $175(\mathrm{n}=1)$ \\
\hline
\end{tabular}

a -4 households shared cisterns, 5 households shared tinacos, and 2 shared tambos; this shows the adjusted volume per household after accounting for sharing.

In general, the per-liter costs of each water source used in the model were very similar to values reported in the interviews for households that paid a per-liter rate; the biggest discrepancy was the number of households who reported receiving water for free or a flat fee. Installation costs and expected lifespans were hard to obtain, since interviewed households did not know how much they paid for their infrastructure installation and were not sure how long they expected it to last. Reported household sizes were higher than the 3.4-person average reported in the Mexican Census (INEGI) which was expected since the interviews targeted households in areas known to have IWS, which are expected to be less affluent, more densely populated parts of the city. 


\section{Drivers of Household Water Costs}

To identify the greatest drivers of household water costs, the difference in average annual household costs (for 95\% reliability) between the "base" case and variable high and low ranges was determined with a one-at-a-time (local) sensitivity analysis (Figure 6). Results are shown for both the low IWS scenario (4 hours/week of piped water supply) and the medium IWS scenario (12 hours/week). The CWS scenario analysis is similar to the medium IWS scenario since their water sources are the same.

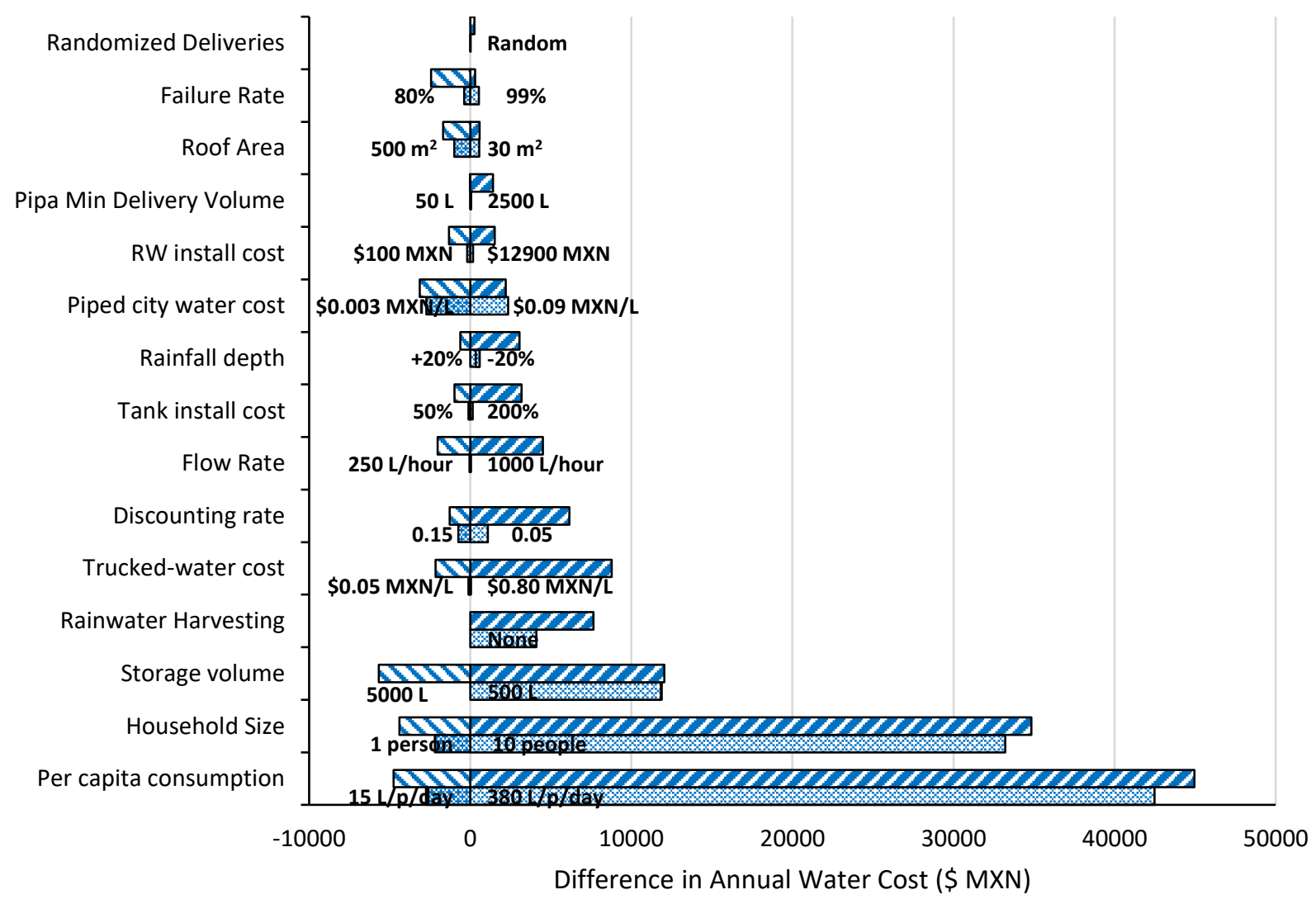

๑Low IWS Schedule $\square$ Medium IWS Schedule

Figure 6. One-at-a-time (local) sensitivity analysis results. One factor at a time was changed to an extreme value while the others were kept at the baseline value. Reliability was set to $95 \%$ and an average annual cost was output. The annual cost difference between baseline scenario and adjusted parameters are shown for the medium IWS scenario (12 hours per week) and low IWS scenario (4 hours per week). 
Due to a lack of data typical in IWS settings, there were several model variables for which it was difficult to find reliable empirical estimates (including trucked-water minimum delivery volume, rainwater harvesting and storage tank installation costs, per liter trucked-water costs). Sensitivity analysis results show that many of these variables had a minimal effect on annual costs, although a few (such as per liter trucked water costs) did change model results significantly. Some variables became more or less significant depending on the household's water piped water supply schedule: for example, per liter trucked water costs affected annual household costs more under low IWS than medium IWS. These results demonstrate that better data is critical to building accurate water models, especially in IWS areas where water costs/reliability depend on multiple factors. A household survey similar to our household interviews but at a much larger scale could provide much needed insights into the MCMA area and allow for accurate modeling of water resource.

Sensitivity analysis results show that the costs of coping with IWS tended to be driven by household characteristics such as total household consumption (per capita consumption and household size), storage capacity, and roof area, although water distribution system characteristics (such as available hours of city water supply, piped water rates, and piped water flow rate) also greatly affected coping costs. Based on these results, two household characteristics were selected to be explored in more detail in the next section: household water consumption and storage tank volume.

Household water consumption. In our model, average household size and per capita water consumption were multiplied to determined average daily household water consumption. However, interview results showed that both household size and per capita consumption varied significantly between households. In Figure 7a we examine varying per capita water consumption (varying household size would show the similar results, since both are directly related to daily household consumption) for both medium and low IWS scenarios with and without rainwater harvesting. Results show that once 
consumption increases past the point where piped water can meet the household's needs, costs increase at a faster rate since more expensive water sources are required at this higher level of consumption. This inflection point varies between IWS schedules and rainwater harvesting decisions, but is between 70-120 liters per capita per day for a household size of 3.4 people. This inflection point is also dependent on the piped water flow rate; lower flow rates will require more hours of supply to meet household needs. IWS is often accompanied by low water pressure that is variable between neighborhoods, so it is important to account for water pressure when measuring water supply (Galaitsi et al., 2016; Guragai et al., 2017; Majuru et al., 2016). Additionally, households with IWS often reserve water-intensive activities (e.g. doing laundry, washing floors, etc) for days when water supply is turned on (Majuru et al., 2016), however we were not able to find any data quantifying how much these water use decisions affected daily water consumption. Therefore, this demand management was not accounted for in the model; target water consumption was assumed to be constant. Incorporating demand management into the model would allow total water consumption to increase without increasing costs as much, especially for IWS schedules with many hours of supply on one day per week.

Household storage capacity. Although the model is able to output the optimal storage tank size, the household interview results showed that many households have limited access to storage and so are not able to rely on their optimal storage volume. Storage tank volume was set to a range of fixed values to represent these households with limited access to storage (Figure 7b). Although Figure 3a showed optimal storage volumes of up to 8000 liters, Figure $7 \mathrm{~b}$ shows that most of the cost-saving benefits can be met with much smaller tanks (around 2500 liters); although very large tanks are the optimal since they allow households to harvest more rainwater, a 2500 liter tank will lower costs nearly the same amount. Larger tanks can lower costs especially for households that receive plenty of piped municipal 
water or harvest rainwater. Households with less available piped water or without rainwater harvesting have slightly smaller optimal tank volumes since they have less available cheap water to store.
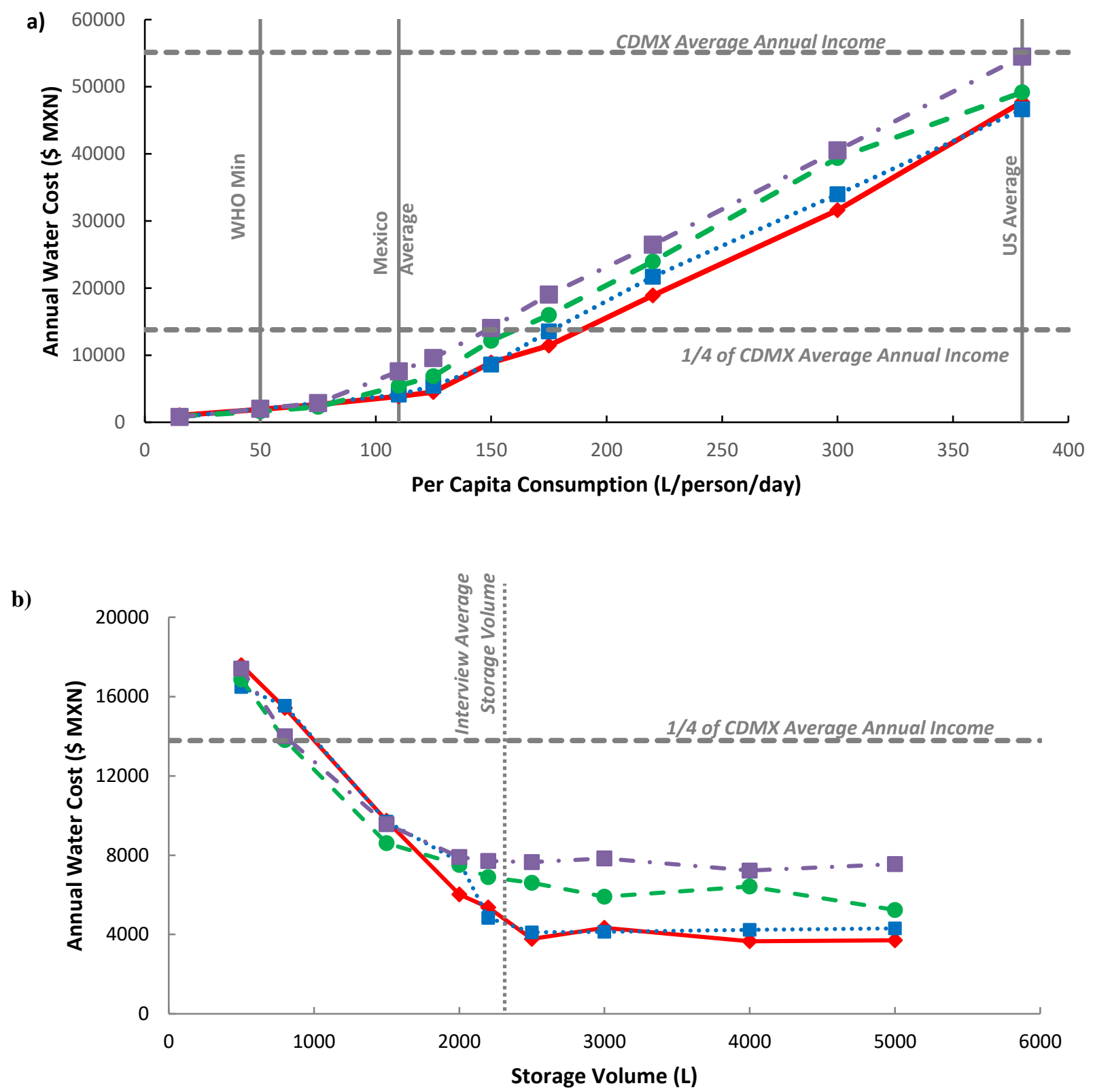

$\longrightarrow 8$ hours, rain $\quad \cdots \cdot . \cdot 8$ hours, No Rain $\quad-\bullet-4$ hours, Rain $\quad-\square-4$ hours, No Rain

Figure 7. Coping costs at $95 \%$ reliability for varying household characteristics. a) Per capita consumption. The vertical lines represent common water consumption benchmarks: the WHO minimum recommendation (Howard \& Bartram, 2003), the Mexico average (INEGI, n.d.), and the US average (Dieter et al., 2018); b) Limited storage volume. Increasing storage volume can lower annual costs, but savings plateau once all the water needed for the week can be stored. Vertical line shows the average storage volume reported by households through interviews. 
When households are limited to very small tanks their water costs rise considerably, since if they are not able to store enough piped municipal water they must turn to alternative, expensive sources to get through the week. The effects of an extremely limited storage volume of 500 liters were explored for various delivery scenarios (Figure 8). When storage is limited to this volume, the total hours of piped delivery matter less than the water delivery schedule. Medium and low IWS schedules produce very similar results, although with sufficient storage we know that the medium scenario is much cheaper, since all of a household's needs can be met with piped water. When storage is limited, however, households may need to purchase trucked water even if they receive enough piped water supply throughout the week (Figure $8 b, c)$. When sufficient storage is available, uncertain delivery times do not affect costs (Figure 3). However, when storage is limited, an IWS schedule with random delivery days does increase household costs, since households cannot plan ahead as well and cannot rely on storage as a buffer (Figure 8d). When the 12 hours of delivery per week are split and delivered on two non-consecutive days (e.g. 6 hours on Monday and 6 hours on Thursday) the costs of water delivery are greatly decreased (Figure 8e). For households with limited storage volume, water utilities can optimize the household's use of piped water and decrease their costs by supplying water on more non-consecutive days for shorter durations without changing the total volume of water delivered per week. 

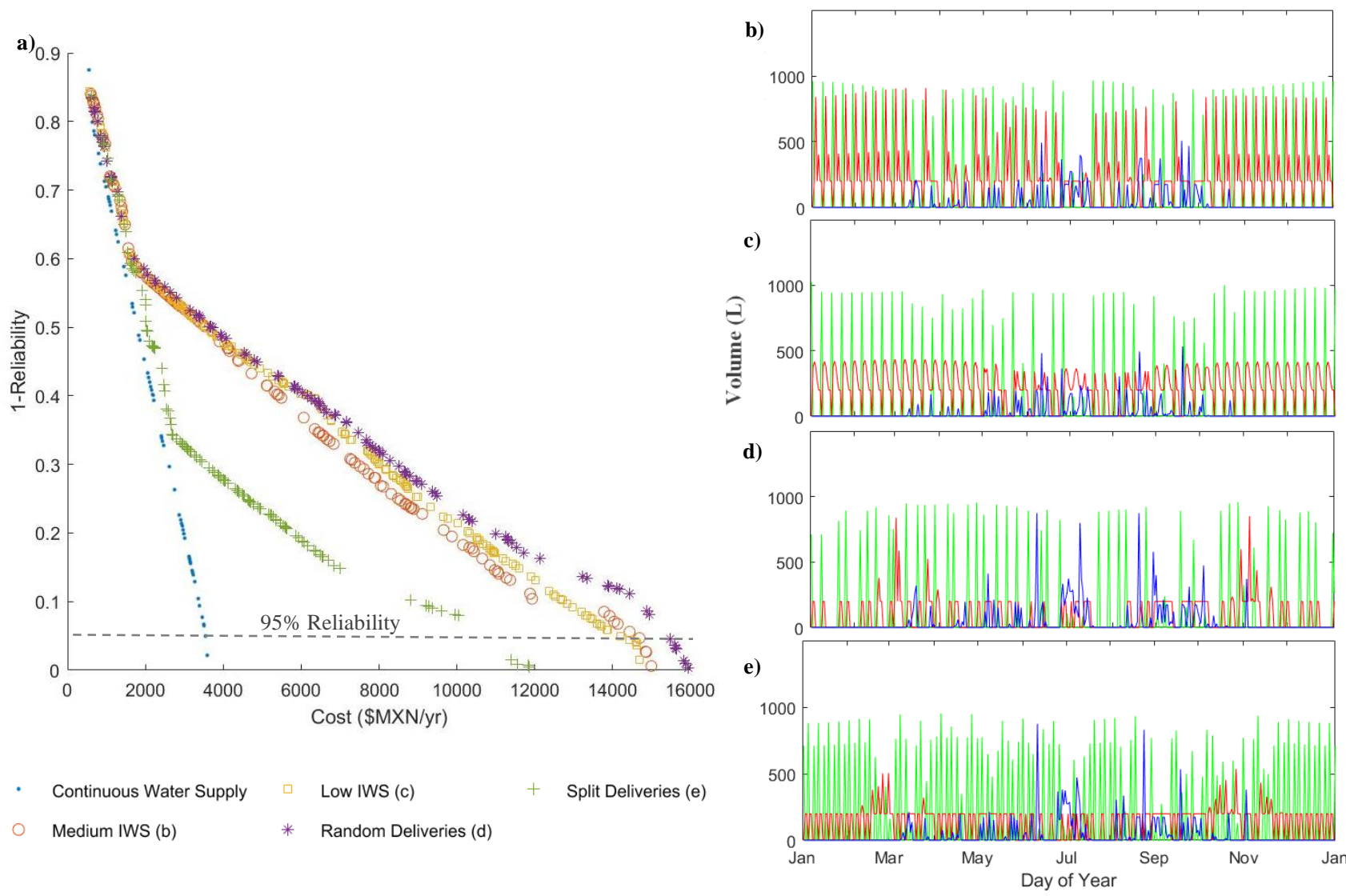

- Piped Municipal Water — Trucked Water

Figure 8. Household cost and reliability trade-off under a set, limited storage volume of 500 liters. a) Pareto front, symbol shapes represent the different water supply scenarios. Volume (L) obtained from each water source on each day throughout the year to achieve 95\% reliability for: b) Medium IWS (12 hours per week); c) Low IWS (4 hours per week); d) Randomized-Medium IWS (12 hours delivered on one random day per week); e) Split-Medium IWS ( 6 hours of supply delivered on Monday plus 6 hours of supply delivered on Thursday). The CWS scenario (with unlimited storage) is plotted in a) for reference.

The seasonal breakdown of water sources changes significantly when storage is limited. Much less rainwater harvesting is possible with such a small tank volume (it can provide only around $10 \%$ of summer water sources), so there is less seasonal variation in optimal water sources (Figure 9). The breakdown of water sources is essentially the same for medium and low IWS schedules when storage is so limited; the limiting factor is no longer hours of water supply but rather ability to store piped water 
(Figure 9a,b). A random IWS delivery schedule also has a much bigger impact on household water supply when storage is limited, especially during the winter when over $75 \%$ of household water must be purchased from water trucks, since they are not able to store sufficient piped water and may have to wait nearly two weeks between deliveries (Figure 9c). However, when the 12 hours of weekly water delivery are delivered on two non-consecutive days, households can make better use of their small storage container and can use nearly twice as much piped water and about one-third less trucked water (Figure 9d).

a)

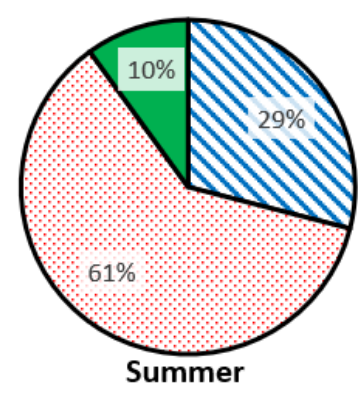

c) 500 L Storage: Random Deliveries (Medium IWS)

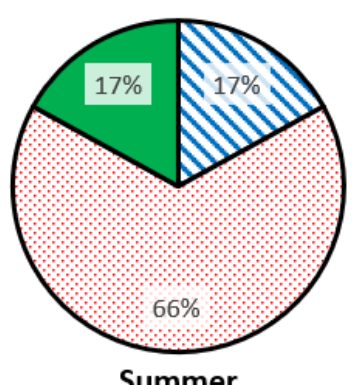

Summer
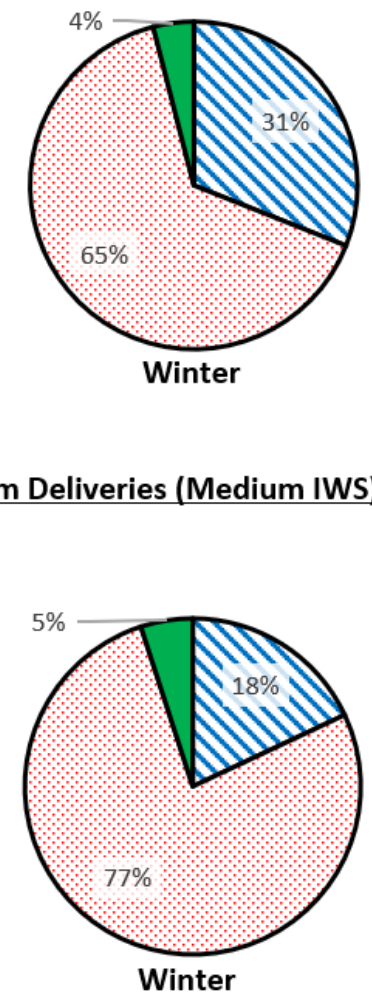

b)

d) 500 L Storage: Split Deliveries (Medium IWS)

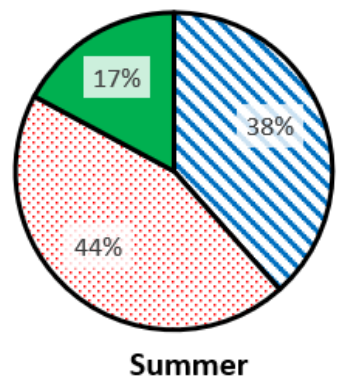

$\mathbb{\Delta}$ Piped-City $\square$ Rain $\square$ Truck

Figure 9. Fraction of water provided by each water source seasonally when storage was limited to $500 \mathrm{~L}$ calculated for each municipal piped water scenario at 95\% reliability for both summer (May-October) and winter (NovemberApril) for four water-supply scenarios: a) Medium IWS schedule); b) Low IWS schedule; c) Randomized-Medium IWS schedule; and d) Medium IWS schedule split between two nonconsecutive delivery days. 


\section{Conclusion}

Our model reveals several implications for water management in IWS cities. First, cities can drastically lower residents' water costs by focusing on delivering a "sufficient" total weekly volume of piped water. Our model finds that this is around five hours of supply per week at a flow rate of 500 liters/hour for an average sized household that consumes the Mexico per capita average of water. However, this minimum required delivery ranges widely based on household size, per capita consumption, and water delivery pressure; households with more people and lower water pressure require more hours of supply. This is consistent with the recommendation by Taylor et al. that demand satisfaction be used as a metric of IWS (Taylor et al., 2019). By focusing on delivering enough water to meet household demand (or at least a minimum "sufficient" water volume) cities can make IWS more equitable.

Secondly, the model demonstrates the importance of household water storage. With sufficient storage, households can mitigate the coping costs and uncertainties associated with low IWS schedules, unscheduled delivery days, and temporary water shortages. Storage also allows households to harvest rainwater, an essentially "free" water source. Storage of 2500 liters is enough to gain most of the benefits of storage, although more rainwater can be collected with a tank up to 8000 liters. When households have limited access to storage, either due to financial or space constraints, the total number of hours of piped delivery has less of an effect on water reliability than the delivery schedule. Water utilities can help households with limited access to storage by splitting water deliveries up to nonconsecutive days to allow these households make better use of their storage and keeps costs low. However, household storage has several drawbacks. First, extensive research has shown that microbial water quality deteriorates in household storage tanks (Elala et al., 2011; Jagals et al., n.d.; John et al., 2014; Kumpel \& Nelson, 2013; Levy Karen et al., 2008; Wright et al., 2004) so proper water storage techniques must be followed. Second, Eakin et al. argue that expecting socioeconomically disadvantaged households to provide their own water resiliency, while cities provide reliable piped water supply to wealthier areas, exacerbates 
inequalities and perpetuates poverty traps (Eakin et al., 2016). Finally, although the cost/reliability benefits of increased storage investment may quickly pay for themselves, many socioeconomically disadvantaged households are renters without the ability to install permanent, large storage features (such as underground cisterns or plumbed roof ranks) or may lack the upfront capital or space needed to install such storage systems. Cities could help these households by subsidizing storage for households in neighborhoods that are known to have unreliable water supply or incentivizing landlords to install more household storage. Interview results show that households often share storage infrastructure with their neighbors, so even subsidized neighborhood-level storage may be beneficial.

Finally, the model finds that rainwater harvesting is economically favorable for households in all watersupply scenarios, although it is especially favorable for those with extremely limited access to piped water. This contrasts slightly with a recent paper by Concha Larrauri et al. who found that found that rainwater harvesting was not typically economically beneficial for domestic water users, and argued that rainwater harvesting programs be aimed at commercial buildings instead (Concha Larrauri et al., 2019). Their spatial analysis does not consider all the nuances of IWS, however, they do conclude that areas where households rely primarily on trucked water could benefit from rainwater harvesting, which agrees with our results. Concha Larrauri et al. base these conclusions on the current subsidized tariff structure. Campisano et al. assert that this discrepancy is common in rainwater harvesting financial analysis, where the most important factor typically considered is the price of water. Since water is often heavily subsidized, either directly or through government-funded infrastructure projects, the value of rainwater is often minimal, especially in developed areas with robust water supply and infrastructure (Campisano et al., 2017). Our model sets the price of municipal piped water at $\$ 0.05 /$ liter; Concha Larrauri et al. use a lower number. Their results may be more in line with our household interviews where many of households reported receiving free piped water, or water based on a flat monthly rate regardless of use, in which case investing in a rainwater harvesting system would not make financial sense. Only when water 
prices are higher (either due to higher tariffs, or lack of piped water causing residents to purchase trucked water) do we find that rainwater harvesting makes financial sense. However, this conclusion neglects the savings experienced at the community level, including decreased reliance on the over-expended aquifer and delayed need for expensive infrastructure upgrades. Although our rainwater harvesting conclusions may not reflect the individual household's experience, they do account for the supply cost of water (Rogers et al., 2002).

These sorts of vast uncertainties due to minor assumptions are common in IWS systems since these areas often lack data necessary for water modeling. Therefore, the integration of additional field-based data collection and modeling of households within their broader systems is crucial to both understanding and planning for resilient urban water systems. Our sensitivity analysis results demonstrate that more data is needed, especially about specific household characteristics (e.g. roof area, hours of supply, piped water flow rate, etc.) to accurately determine its water reliability. This study, and others like it, could be strengthened by further data collection similar to a larger scale household survey. Even factors that are well documented, such as number of people per household (INEGI, n.d.) and rainfall (Carrera-Hernández \& Gaskin, 2007) often vary widely across the city. Often, water reliability varies greatly across small distances and brief time periods (Jaeger et al., 2017) so a system-wide analysis must consider this heterogeneity. Additionally, these are relatively simple models could be changed drastically due to household behavior change, adoption of new technologies, corruption, other unforeseen complications. Additional field work is critical in this area to account for these on the ground realities.

Megacities of the future will continue to face water challenges and increasingly intermittent water supplies as populations grow and stress limited water resources. In addition, water supplies in the future will likely experience more system shocks, stress events, and increased uncertainty (IPCC, 2014). Recent cuts to Mexico City's water supply (for example, the Mega Corte in October 2018 and the drought of 
2010) are recent examples of stress events. Interview results showed that households behaved differently during these times of water stress, many reported that their only experience purchasing trucked water was after piped water service was disrupted during the earthquake. Accounting for household actions in water models, therefore, is vital when planning for these events and working to increase resiliency. Traditional supply-side interventions are well explored but only tell half of the story of possible solutions. In IWS systems, household decisions regarding water sources and storage must also be included since they affect not only their own reliability but also the water-supply dynamics of the entire city. We have demonstrated that household level water supply decisions (e.g. household level infrastructure and behavior) can be an important complement to traditional supply-side interventions, especially as decentralized water supply systems have been considered as more resilient options (Biggs et al., 2010; Chelleri et al., 2015). Recent urban resilience literature has called for the development of models across different scales to evaluate tradeoffs between actions by different actors (e.g. households vs water utilities vs large investors) and at different scales. (St. George Freeman et al., 2020; Zhang \& Li, 2018). Using RBFNs to model these decisions is an important step towards including household-level decisions and IWS in an integrated assessment of options across a range of scales of urban water systems, a desperately needed improvement in modeling urban water supply in the developing world. 


\section{Supporting Information}

\section{2-Year Simulation Model}

The optimization model is part of a larger simulation model that calculates a household's water sources, storage, and consumption. Equation SI1 below shows the storage calculation.

$$
V_{t+1}^{\text {storage }}=V_{t}^{\text {storage }}+V_{t}^{\text {muni }}+V_{t}^{\text {truck }}+V_{t}^{\text {rain }}-V_{t}^{\text {consume }}-V_{t}^{\text {spill }}
$$

The volume of water stored ( $V^{\text {storage }}$ ) for day $t+1$ is the sum of storage for the previous day $t$, the volume of water supplied from the three different water sources $\left(V^{\text {muni }}, V^{\text {truck }}, V^{\text {rain }}\right)$, the volume of water consumed by the household for day $t\left(V^{\text {consume }}\right)$, and a spill factor $\left(V^{\text {spill }}\right)$. The volume of city-supplied water $V^{\text {muni }}$ for day $t$ is given by Equation SI2.

$$
V_{t}^{\text {muni }}=\operatorname{Min}\left(u_{t}^{\text {muni }}, \operatorname{Lim}_{t}^{\text {muni }}\right)
$$

In Equation 8, $u^{\text {muni }}$ is the RBFN recommended volume of city-supplied water for day $t$ and the $\operatorname{Lim}^{\text {muni }}$ is the volume of water available from the city according to the IWS schedule for day $t$. This constraint is necessary to limit the volume of city water that is available to a household to the volume available for that day's IWS schedule.

The volume of trucked-water purchased on day $t, V^{\text {truck }}$ is determined by the RBFN decision for that day ( $u^{\text {truck }}$ ) subjected to additional constraints. If the RBFN recommends trucked water be purchased for that day $\left(u^{\text {truck }}>0\right)$, then the volume of trucked-water must be at least equal to some reasonable delivery volume $\mathrm{Lim}^{\text {truck }}$ that represents the smallest volume of water a water truck driver would be willing to deliver (Equation SI3). This prevents the model from ordering unrealistically small volumes of water whenever water is needed rather than relying on storage.

$$
V_{t}^{\text {truck }}=\operatorname{Max}\left(u_{t}^{\text {truck }}, \text { Lim }^{\text {truck }}\right)
$$


Else, if the RBFN does not recommend trucked water be purchased for that day $\left(u^{\text {truck }}=0\right)$, then the volume of trucked-water for that day is zero.

The volume of rainwater harvested $V^{\text {rain }}$ on day $t$ is a function of the depth of rainfall and the area of the collection surface (Equation SI4).

$$
V_{t}^{\text {rain }}=D_{\text {rain }} * A *(1-L F)
$$

$D_{\text {rain }}$ is the depth of rainfall on day $t ; A$ is the area over which rainwater is collected (typically the household's roof area); and $L F$ is the fraction of harvested rainwater lost to evaporation, first flush, and other collection inefficiencies.

The volume of water consumed by the household for day $t$ is either the target consumption $\left(V^{\text {target }}\right)$ if sufficient water is available, or else whatever volume is available in the storage tank on day $t\left(V^{\text {storage }}\right)$ as seen in Equation SI5.

$$
V_{t}^{\text {consume }}=\operatorname{Min}\left(V^{\text {target }}, V_{t}^{\text {storage }}\right)
$$

If the total volume to be stored is greater than the storage tank capacity, then the excess water is subtracted as spill (Equation SI6).

$$
V_{t}^{\text {spill }}=V_{t}^{\text {storage }}-V^{\text {tank }}
$$




\section{References}

Abdulla, F. A., \& Al-Shareef, A. W. (2009). Roof rainwater harvesting systems for household water supply in Jordan. Desalination, 243(1), 195-207. https://doi.org/10.1016/j.desal.2008.05.013

Abubakar, I. R. (2018). Strategies for coping with inadequate domestic water supply in Abuja, Nigeria. Water International, 43(5), 570-590. https://doi.org/10.1080/02508060.2018.1490862

Andey, S. P., \& Kelkar, P. S. (2009). Influence of Intermittent and Continuous Modes of Water Supply on Domestic Water Consumption. Water Resources Management, 23(12), 2555-2566. https://doi.org/10.1007/s11269-008-9396-8

Apoorva, R., Biswas, D., \& Srinivasan, V. (2018). Do household surveys estimate tap water use accurately? Evidence from pressure-sensor based estimates in Coimbatore, India. Journal of Water, Sanitation and Hygiene for Development, 8(2), 278-289. https://doi.org/10.2166/washdev.2018.127

Baisa, B., Davis, L. W., Salant, S. W., \& Wilcox, W. (2010). The welfare costs of unreliable water service. Journal of Development Economics, 92(1), 1-12. https://doi.org/10.1016/j.jdeveco.2008.09.010

Biggs, C. T. B., Ryan, C. J. R., \& Wiseman, J. R. (2010). Distributed Systems: A Design Model for Sustainable and Resilient Infrastructure (Report No. 3; Distributed Systems Briefing Paper). Victorian Eco-Innovation Lab. http://minerva-access.unimelb.edu.au/handle/11343/165216

Bivins, A. W., Sumner, T., Kumpel, E., Howard, G., Cumming, O., Ross, I., Nelson, K., \& Brown, J. (2017). Estimating Infection Risks and the Global Burden of Diarrheal Disease Attributable to Intermittent Water Supply Using QMRA. Environmental Science \& Technology, 51(13), 75427551. https://doi.org/10.1021/acs.est.7b01014

Burt, Z., \& Isha, R. (2014). Storage and Non-Payment: Persistent Informalities within the Formal Water Supply of Hubli-Dharwad, India. Water Alternatives, 7(1), 106-120.

Campisano, A., Butler, D., Ward, S., Burns, M. J., Friedler, E., DeBusk, K., Fisher-Jeffes, L. N., Ghisi, E., Rahman, A., Furumai, H., \& Han, M. (2017). Urban rainwater harvesting systems: Research, implementation and future perspectives. Water Research, 115, 195-209. https://doi.org/10.1016/j.watres.2017.02.056

Carrera-Hernández, J. J., \& Gaskin, S. J. (2007). Spatio temporal analysis of daily precipitation and temperature in the Basin of Mexico. Journal of Hydrology, 336(3), 231-249. https://doi.org/10.1016/j.jhydrol.2006.12.021

Chelleri, L., Schuetze, T., \& Salvati, L. (2015). Integrating resilience with urban sustainability in neglected neighborhoods: Challenges and opportunities of transitioning to decentralized water management in Mexico City. Habitat International, 48, 122-130. https://doi.org/10.1016/j.habitatint.2015.03.016

Choe, K., Varley, R. C. G., \& Bijlani, H. U. (1996). Coping with Intermittent Water Supply: Problems and Prospects (No. 26; Activity Report). USAID.

Coelho, S. T., James, S., Sunna, N., Abu Jaish, A., \& Chatila, J. (2003). Controlling water quality in intermittent supply systems. Water Science and Technology: Water Supply, 3(1-2), 119-125. https://doi.org/10.2166/ws.2003.0094 
Concha Larrauri, P., Campos Gutierrez, J. P., Lall, U., \& Ennenbach, M. (2019). A City Wide Assessment of the Financial Benefits of Rainwater Harvesting in Mexico City. Journal of the American Water Resources Association, n/a(n/a). https://doi.org/10.1111/1752-1688.12823

Coppola, A., Fernholz, F., \& Glenday, G. (2014). Estimating the Economic Opportunity Cost of Capital for Public Investment Projects: An Empirical Analysis of the Mexican Case. The World Bank. https://doi.org/10.1596/1813-9450-6816

Coulibaly, L., Jakus, P. M., \& Keith, J. E. (2014). Modeling water demand when households have multiple sources of water. Water Resources Research, 50(7), 6002-6014. https://doi.org/10.1002/2013WR015090

Cybenko, G. (1989). Approximation by superpositions of a sigmoidal function. Mathematics of Control, Signals and Systems, 2(4), 303-314. https://doi.org/10.1007/BF02551274

Dieter, C. A., Maupin, M. A., Caldwell, R. R., Harris, M. A., Ivahnenko, T. I., Lovelace, J. K., Barber, N. L., \& Linsey, K. S. (2018). Estimated use of water in the United States in 2015. In Estimated use of water in the United States in 2015 (USGS Numbered Series No. 1441; Circular, Vol. 1441, p. 76). U.S. Geological Survey. https://doi.org/10.3133/cir1441

Eakin, H., Lerner, A. M., Manuel-Navarrete, D., Hernández Aguilar, B., Martínez-Canedo, A., Tellman, B., Charli-Joseph, L., Fernández Álvarez, R., \& Bojórquez-Tapia, L. (2016). Adapting to risk and perpetuating poverty: Household's strategies for managing flood risk and water scarcity in Mexico City. Environmental Science \& Policy, 66, 324-333. https://doi.org/10.1016/j.envsci.2016.06.006

Elala, D., Labhasetwar, P., \& Tyrrel, S. F. (2011). Deterioration in water quality from supply chain to household and appropriate storage in the context of intermittent water supplies. Water Science and Technology: Water Supply, 11(4), 400-408. https://doi.org/10.2166/ws.2011.064

Elliott, M., Foster, T., MacDonald, M. C., Harris, A. R., Schwab, K. J., \& Hadwen, W. L. (2019). Addressing how multiple household water sources and uses build water resilience and support sustainable development. Npj Clean Water, 2(1). https://doi.org/10.1038/s41545-019-0031-4

Elliott, M., MacDonald, M. C., Chan, T., Kearton, A., Shields, K. F., Bartram, J. K., \& Hadwen, W. L. (2017). Multiple Household Water Sources and Their Use in Remote Communities With Evidence From Pacific Island Countries: MULTIPLE HOUSEHOLD WATER SOURCES IN PICS. Water Resources Research, 53(11), 9106-9117. https://doi.org/10.1002/2017WR021047

Espinosa-García, A. C., Díaz-Ávalos, C., González-Villarreal, F. J., Val-Segura, R., Malvaez-Orozco, V., \& Mazari-Hiriart, M. (2015). Drinking Water Quality in a Mexico City University Community: Perception and Preferences. EcoHealth, 12(1), 88-97. https://doi.org/10.1007/s10393-014-0978-z

Fuentes-Galván, M. L., Ortiz Medel, J., \& Arias Hernández, L. A. (2018). Roof Rainwater Harvesting in Central Mexico: Uses, Benefits, and Factors of Adoption. Water, 10(2), 116. https://doi.org/10.3390/w10020116

Galaitsi, S. E., Russell, R., Bishara, A., Durant, J. L., Bogle, J., \& Huber-Lee, A. (2016). Intermittent Domestic Water Supply: A Critical Review and Analysis of Causal-Consequential Pathways. Water, 8(7), 274. https://doi.org/10.3390/w8070274

Garcia, S. (2016, July 6). How capturing rain could save Mexico City from a water crisis. The Guardian. https://www.theguardian.com/global-development-professionals-network/2016/jul/06/capturingrain-save-mexico-city-water-crisis 
Giuliani, M., Castelletti, A., Pianosi, F., Mason, E., \& Reed, P. M. (2016). Curses, Tradeoffs, and Scalable Management: Advancing Evolutionary Multiobjective Direct Policy Search to Improve Water Reservoir Operations. Journal of Water Resources Planning and Management, 142(2), 04015050. https://doi.org/10.1061/(ASCE)WR.1943-5452.0000570

Giuliani, M., Mason, E., Castelletti, A., Pianosi, F., \& Soncini-Sessa, R. (2014). Universal approximators for direct policy search in multi-purpose water reservoir management: A comparative analysis. IFAC Proceedings Volumes, 47(3), 6234-6239. https://doi.org/10.3182/20140824-6-ZA1003.01962

Gómez-Valdez, Monserrat I., Palerm-Viqueira, J., Gómez-Valdez, M. I., \& Palerm-Viqueira, J. (2015). Abastecimiento de agua potable por pipas en el Valle de Texcoco, México. Agricultura, Sociedad y Desarrollo, 12(4), 567-586.

Gómez-Valdez, Monserrat Iliana, Palerm-Viqueira, J., Gómez-Valdez, M. I., \& Palerm-Viqueira, J. (2016). El abasto de agua por pipa en el valle de Texcoco, México. Tecnología y Ciencias Del Agua, 7(2), 133-148.

Google, \& Instituto Nacional de Estadistica y Geografia (INEGI). (2018). Satellite Imagery for Mexico City, Mexico.

Grabinsky, A. (2019, August 16). Mexico City's Rain-Harvesting Program Could Change How Cities Manage Water. Next City. https://nextcity.org/daily/entry/mexico-citys-rain-harvesting-programcould-change-how-cities-manage-water

Grant, S. B., Fletcher, T. D., Feldman, D., Saphores, J.-D., Cook, P. L. M., Stewardson, M., Low, K., Burry, K., \& Hamilton, A. J. (2013). Adapting Urban Water Systems to a Changing Climate: Lessons from the Millennium Drought in Southeast Australia. Environmental Science \& Technology, 47(19), 10727-10734. https://doi.org/10.1021/es400618z

Gulyani, S., Talukdar, D., \& Mukami Kariuki, R. (2005). Universal (Non)service? Water Markets, Household Demand and the Poor in Urban Kenya. Urban Studies, 42(8), 1247-1274. https://doi.org/10.1080/00420980500150557

Guragai, B., Takizawa, S., Hashimoto, T., \& Oguma, K. (2017). Effects of inequality of supply hours on consumers' coping strategies and perceptions of intermittent water supply in Kathmandu Valley, Nepal. Science of The Total Environment, 599-600, 431-441. https://doi.org/10.1016/j.scitotenv.2017.04.182

Gurung, Y., Zhao, J., Kumar KC, B., Wu, X., Suwal, B., \& Whittington, D. (2017). The costs of delay in infrastructure investments: A comparison of 2001 and 2014 household water supply coping costs in the Kathmandu Valley, Nepal. Water Resources Research, 53(8), 7078-7102. https://doi.org/10.1002/2016WR019529

Hadka, D., \& Reed, P. (2013). Borg: An Auto-Adaptive Many-Objective Evolutionary Computing Framework. Evolutionary Computation, 21(2), 231-259.

Hashimoto, T., Stedinger, J. R., \& Loucks, D. P. (1982). Reliability, resiliency, and vulnerability criteria for water resource system performance evaluation. Water Resources Research, 18(1), 14-20. https://doi.org/10.1029/WR018i001p00014

Howard, G., \& Bartram, J. (2003). Domestic Water Quantity, Service Level and Health. World Health Organization, 39. 
INEGI, I. N. de E. y G. (n.d.). Instituto Nacional de Estadística y Geografía. INEGI. Retrieved April 26, 2019, from https://www.inegi.org.mx/default.html

Inter-American Development Bank (IDB). (2011, November 10). How Mexico became the world's top consumer of bottled water.

IPCC. (2014). Climate Change 2014: Impacts, Adaptation, and Vulnerability. Part A: Global and Sectoral Aspects. Contribution of Working Group II to the Fifth Assessment Report of the Intergovernmental Panel on Climate Change (p. 1132). Cambridge University Press. https://www.ipcc.ch/assessment-report/ar6/

Isla Urbana. (n.d.). Isla Urbana. Retrieved December 13, 2018, from http://islaurbana.mx/

Jaeger, W. K., Amos, A., Bigelow, D. P., Chang, H., Conklin, D. R., Haggerty, R., Langpap, C., Moore, K., Mote, P. W., Nolin, A. W., Plantinga, A. J., Schwartz, C. L., Tullos, D., \& Turner, D. P. (2017). Finding water scarcity amid abundance using human-natural system models. Proceedings of the National Academy of Sciences, 114(45), 11884-11889. https://doi.org/10.1073/pnas.1706847114

Jagals, P., Bokako, T., \& Grabow, W. (n.d.). Changing consumer water-use patterns and their effect on microbiological water quality as a result of an engineering intervention. 4.

Jayawardena, A. W., Fernando, D. A. K., \& Zhou, M. C. (1997). Comparison of multi-layer perceptron and radial basis function network as tools for flood forecasting. Proc. North Am. Water and Envir. Conf, 457-458.

John, V., Jain, P., Rahate, M., \& Labhasetwar, P. (2014). Assessment of deterioration in water quality from source to household storage in semi-urban settings of developing countries. Environmental Monitoring and Assessment, 186(2), 725-734. https://doi.org/10.1007/s10661-013-3412-z

Kimmelman, M. (2017, February 17). Mexico City, Parched and Sinking, Faces a Water Crisis. The New York Times. https://www.nytimes.com/interactive/2017/02/17/world/americas/mexico-citysinking.html, https://www.nytimes.com/interactive/2017/02/17/world/americas/mexico-citysinking.html

Klassert, C., Sigel, K., Gawel, E., \& Klauer, B. (2015). Modeling Residential Water Consumption in Amman: The Role of Intermittency, Storage, and Pricing for Piped and Tanker Water. Water, 7(7), 3643-3670. https://doi.org/10.3390/w7073643

Kumar, M. D. (2004). Roof Water Harvesting for Domestic Water Security: Who Gains and Who Loses? Water International, 29(1), 43-53. https://doi.org/10.1080/02508060408691747

Kumpel, E., \& Nelson, K. L. (2013). Comparing microbial water quality in an intermittent and continuous piped water supply. Water Research, 47(14), 5176-5188. https://doi.org/10.1016/j.watres.2013.05.058

Kumpel, E., \& Nelson, K. L. (2016). Intermittent Water Supply: Prevalence, Practice, and Microbial Water Quality. Environmental Science \& Technology, 50(2), 542-553. https://doi.org/10.1021/acs.est.5b03973

Kumpel, E., Woelfle-Erskine, C., Ray, I., \& Nelson, K. L. (2017). Measuring household consumption and waste in unmetered, intermittent piped water systems. Water Resources Research, 53(1), 302315. https://doi.org/10.1002/2016WR019702 
Lerner, A. M., Eakin, H. C., Tellman, E., Bausch, J. C., \& Hernández Aguilar, B. (2018). Governing the gaps in water governance and land-use planning in a megacity: The example of hydrological risk in Mexico City. Cities, 83, 61-70. https://doi.org/10.1016/j.cities.2018.06.009

Levy Karen, Nelson Kara L., Hubbard Alan, \& Eisenberg Joseph N.S. (2008). Following the Water: A Controlled Study of Drinking Water Storage in Northern Coastal Ecuador. Environmental Health Perspectives, 116(11), 1533-1540. https://doi.org/10.1289/ehp.11296

Liao, Y., Fang, S.-C., \& Nuttle, H. L. W. (2003). Relaxed conditions for radial-basis function networks to be universal approximators. Neural Networks, 16(7), 1019-1028. https://doi.org/10.1016/S08936080(02)00227-7

Lin, G.-F., \& Chen, L.-H. (2004). A non-linear rainfall-runoff model using radial basis function network. Journal of Hydrology, 289(1), 1-8. https://doi.org/10.1016/j.jhydrol.2003.10.015

Londhe, A., Talati, J., Singh, L. K., Vilayasseril, M., Dhaunta, S., Rawlley, B., Ganapathy, K. K., \& Mathew, R. P. (2004). Urban-hinterland water transactions: A scoping study of six class I Indian cities. IWMI-Tata Water Policy Program Annual Partners Meet 2004. https://cgspace.cgiar.org/handle/10568/38064

Luthy, R. G., Sharvelle, S., \& Dillon, P. (2019). Urban Stormwater to Enhance Water Supply. Environmental Science \& Technology, 53(10), 5534-5542. https://doi.org/10.1021/acs.est.8b05913

Majuru, B., Suhrcke, M., \& Hunter, P. R. (2016). How Do Households Respond to Unreliable Water Supplies? A Systematic Review. International Journal of Environmental Research and Public Health, 13(12). https://doi.org/10.3390/ijerph13121222

Marosi, R. (2017, November 26). Mexico's Housing Debacle: What it's like to live in 325 square feet. Los Angeles Times. http://www.latimes.com/projects/la-me-mexico-housing-chapter-5/

Pattanayak, S. K., Yang, J.-C., Whittington, D., \& Kumar, K. C. B. (2005). Coping with unreliable public water supplies: Averting expenditures by households in Kathmandu, Nepal. Water Resources Research, 41(2). https://doi.org/10.1029/2003WR002443

Pianosi, F., Quach Thi, X., \& Soncini-Sessa, R. (2011). Artificial Neural Networks and Multi Objective Genetic Algorithms for water resources management: An application to the Hoabinh reservoir in Vietnam. IFAC Proceedings Volumes, 44(1), 10579-10584. https://doi.org/10.3182/20110828-6IT-1002.02208

Quinn, J. D., Reed, P. M., \& Keller, K. (2017). Direct policy search for robust multi-objective management of deeply uncertain socio-ecological tipping points. Environmental Modelling \& Software, 92, 125-141. https://doi.org/10.1016/j.envsoft.2017.02.017

Rahman, A., Dbais, J., Mitchell, C., Ronaldson, P., \& Shrestha, S. (2007). Study of Rainwater Tanks as a Source of Alternative Water Supply in a Multistory Residential Building in Sydney, Australia. World Environmental and Water Resources Congress 2007: Restoring Our Natural Habitat. https://doi.org/10.1061/40927(243)596

Roebuck, R. M., Oltean-Dumbrava, C., \& Tait, S. (2011). Whole life cost performance of domestic rainwater harvesting systems in the United Kingdom. Water and Environment Journal, 25(3), 355-365. https://doi.org/10.1111/j.1747-6593.2010.00230.x 
Rogers, P., de Silva, R., \& Bhatia, R. (2002). Water is an economic good: How to use prices to promote equity, efficiency, and sustainability. Water Policy, 4(1), 1-17. https://doi.org/10.1016/S13667017(02)00004-1

Romero Lankao, P. (2010). Water in Mexico City: What will climate change bring to its history of waterrelated hazards and vulnerabilities? Environment and Urbanization, 22(1), 157-178. https://doi.org/10.1177/0956247809362636

Rosenberg, D. E., Talozi, S., \& Lund, J. R. (2008). Intermittent water supplies: Challenges and opportunities for residential water users in Jordan. Water International, 33(4), 488-504. https://doi.org/10.1080/02508060802474574

Rosenberg, D. E., Tarawneh, T., Abdel-Khaleq, R., \& Lund, J. R. (2007). Modeling integrated water user decisions in intermittent supply systems: Integrated Water User Decisions. Water Resources Research, 43(7). https://doi.org/10.1029/2006WR005340

Shelton, R. E., Baeza, A., Janssen, M. A., \& Eakin, H. (2018). Managing household socio-hydrological risk in Mexico city: A game to communicate and validate computational modeling with stakeholders. Journal of Environmental Management, 227, 200-208. https://doi.org/10.1016/j.jenvman.2018.08.094

Sistema de Aguas de la Ciudad de Mexico (SACMEX). (2006). Informe: Delegación Iztapalapa (Plan Hidráulico Delegacional 2006-2012.).

Sistema de Aguas de la Ciudad de Mexico (SACMEX). (2014). Estudio para determinar las condiciones físicas y operativas de 150 pozos en el alto Lerma (Informe).

Sistema de Aguas de la Ciudad de Mexico (SACMEX). (2017). Tarifas Agua 2018 (No. 230; Gaceta Oficial de la Ciudad México).

St. George Freeman, S., Brown, C., Cañada, H., Martinez, V., Palma Nava, A., Ray, P., Rodriguez, D., Romo, A., Tracy, J., Vázquez, E., Wi, S., \& Boltz, F. (2020). Resilience by design in Mexico City: A participatory human-hydrologic systems approach. Water Security, 9, 100053. https://doi.org/10.1016/j.wasec.2019.100053

Tatar, A., Naseri, S., Sirach, N., Lee, M., \& Bahadori, A. (2015). Prediction of reservoir brine properties using radial basis function (RBF) neural network. Petroleum, 1(4), 349-357. https://doi.org/10.1016/j.petlm.2015.10.011

Taylor, D. D. J., Slocum, A. H., \& Whittle, A. J. (2019). Demand Satisfaction as a Framework for Understanding Intermittent Water Supply Systems. Water Resources Research, 55(7), 52175237. https://doi.org/10.1029/2018WR024124

Tokajian, S., \& Hashwa, F. (2003). Water quality problems associated with intermittent water supply. Water Science and Technology, 47(3), 229-234. https://doi.org/10.2166/wst.2003.0200

Tortajada, C. (2006). Who Has Access to Water? Case Study of Mexico City Metropolitan Area. United Nations Development Programme, 47.

United Nations. (2019). United Nations Demographic Yearbook 2018 (Sixty-Ninth Issue). UN. doi.org/10.18356/50a88046-en-fr

United Nations, Department of Economic and Social Affairs, Population Division. (2019). 2018 Revision of World Urbanization Prospects: Highlights. https://population.un.org/wup/ 
Valdez, M. C., Adler, I., Barrett, M., Ochoa, R., \& Pérez, A. (2016). The Water-Energy-Carbon Nexus: Optimising Rainwater Harvesting in Mexico City. Environmental Processes, 3(2), 307-323. https://doi.org/10.1007/s40710-016-0138-2

van den Berg, C., \& Danilenko, A. (2010). The IBNET Water Supply and Sanitation Performance Blue Book: The International Benchmarking Network for Water and Sanitation Utilities Databook. The World Bank. https://doi.org/10.1596/978-0-8213-8582-1

Vásquez, W. F. (2012). Reliability perceptions and water storage expenditures: Evidence from Nicaragua. Water Resources Research, 48(10). https://doi.org/10.1029/2011WR011024

Whittington, D., Lauria, D. T., \& Mu, X. (1991). A study of water vending and willingness to pay for water in Onitsha, Nigeria. World Development, 19(2), 179-198. https://doi.org/10.1016/0305$750 \mathrm{X}(91) 90254-\mathrm{F}$

WHO, \& UNICEF. (2015). Progress on Sanitation and Drinking Water: 2015 Update and MDG Assessment. World Health Organization.

WHO, \& UNICEF. (2018). Core questions on water, sanitation and hygiene for household surveys: 2018 update.

Wright, J., Gundry, S., \& Conroy, R. (2004). Household drinking water in developing countries: A systematic review of microbiological contamination between source and point-of-use. Tropical Medicine \& International Health, 9(1), 106-117. https://doi.org/10.1046/j.13653156.2003.01160.x

Wutich, A. (2009). Estimating Household Water Use: A Comparison of Diary, Prompted Recall, and Free Recall Methods. Field Methods, 21(1), 49-68. https://doi.org/10.1177/1525822X08325673

Yannopoulos, S., Antoniou, G., Kaiafa-Saropoulou, M., \& Angelakis, A. N. (2017). Historical development of rainwater harvesting and use in Hellas: A preliminary review. Water Science and Technology: Water Supply, 17(4), 1022-1034. https://doi.org/10.2166/ws.2016.200

Zérah, M.-H. (2000). Household strategies for coping with unreliable water supplies: The case of Delhi. Habitat International, 24(3), 295-307. https://doi.org/10.1016/S0197-3975(99)00045-4

Zhang, X., \& Li, H. (2018). Urban resilience and urban sustainability: What we know and what do not know? Cities, 72, 141-148. https://doi.org/10.1016/j.cities.2017.08.009

Zozmann, H., Klassert, C., Sigel, K., Gawel, E., \& Klauer, B. (2019). Commercial Tanker Water Demand in Amman, Jordan-A Spatial Simulation Model of Water Consumption Decisions under Intermittent Network Supply. Water, 11(2), 254. https://doi.org/10.3390/w11020254 